Prepared for the U.S. Department of Energy

under Contract DE-AC05-76RL01830

\title{
Development of a Low-Lift Chiller Controller and Simplified Precooling Control Algorithm - Final Report
}

\author{
N Gayeski J Gagne \\ P Armstrong S Katipamula \\ M Alvira
}

November 2011

Pacific Northwest

NATIONAL LABORATORY

Proudly Operated by Battelle Since 1965 


\title{
DISCLAIMER
}

This report was prepared as an account of work sponsored by an agency of the United States Government. Neither the United States Government nor any agency thereof, nor Battelle Memorial Institute, nor any of their employees, makes any warranty, express or implied, or assumes any legal liability or responsibility for the accuracy, completeness, or usefulness of any information, apparatus, product, or process disclosed, or represents that its use would not infringe privately owned rights. Reference herein to any specific commercial product, process, or service by trade name, trademark, manufacturer, or otherwise does not necessarily constitute or imply its endorsement, recommendation, or favoring by

the United States Government or any agency thereof, or Battelle Memorial Institute. The views and opinions of authors expressed herein do not necessarily state or reflect those of the United States Government or any agency thereof.

\author{
PACIFIC NORTHWEST NATIONAL LABORATORY \\ operated by \\ BATTELLE \\ for the \\ UNITED STATES DEPARTMENT OF ENERGY \\ under Contract DE-AC05-76RL01830 \\ Printed in the United States of America \\ Available to DOE and DOE contractors from the \\ Office of Scientific and Technical Information, \\ P.O. Box 62, Oak Ridge, TN 37831-0062; \\ ph: (865) 576-8401 \\ fax: (865) 576-5728 \\ email: reports@adonis.osti.gov
}

\author{
Available to the public from the National Technical Information Service, \\ U.S. Department of Commerce, 5285 Port Royal Rd., Springfield, VA 22161 \\ ph: (800) 553-6847 \\ fax: (703) 605-6900 \\ email: orders@ntis.fedworld.gov \\ online ordering: http://www.ntis.gov/ordering.htm
}

This document was printed on recycled paper.

(9/2003) 
PNNL-21155

\title{
Development of a Low-Lift Chiller Controller and Simplified Precooling Control Algorithm - Final Report
}

\author{
N Gayeski ${ }^{(a)}$ \\ P Armstrong ${ }^{(b)}$ \\ M Alvira ${ }^{(\mathrm{c})}$ \\ J Gagne ${ }^{(a)}$ \\ S Katipamula, Project Manager
}

November 2011

Prepared for

U.S. Department of Energy

under Contract DE-AC05-76RL01830

Pacific Northwest National Laboratory

Richland, Washington 99352
(a) KGS Buildings, LLC
(b) Masdar Institute of Science and Technology

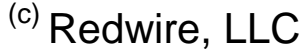





\section{Executive Summary}

KGS Buildings LLC (KGS) and Pacific Northwest National Laboratory (PNNL) have developed a simplified control algorithm and prototype low-lift chiller controller suitable for model-predictive control in a demonstration project of low-lift cooling. Low-lift cooling is a highly efficient cooling strategy conceived to enable low or net-zero energy buildings (Armstrong et al. 2009a, b). A low-lift cooling system consists of a high efficiency low-lift chiller, radiant cooling, thermal storage, and model-predictive control to pre-cool thermal storage overnight on an optimal cooling rate trajectory. We call the properly integrated and controlled combination of these elements a low-lift cooling system (LLCS).

An effective design approach for low-lift cooling is to use building integral thermal mass for thermal storage. This can be accomplished with thermo-active building systems (TABS), where pipe is embedded in concrete to allow for active charging of building thermal mass. This approach can be applied easily to new construction, or to existing buildings undergoing a deep retrofit, where a thin "topping" slab can be applied to existing infrastructure. . A low lift chiller is required to achieve high precooling efficiencies. A low-lift chiller is a chiller than can operate efficiently over a wide range of compressor speed and condensing-evaporating temperature difference. This ability results in very high part-load efficiencies because at low compressor speed not only are flow losses reduced but condenser and evaporator approach temperatures are also improved, i.e. internal temperature lift approaches external temperature lift.

This work addresses two barriers to achieving commercially viable low-lift cooling systems: 1) the lack of chillers that operate efficiently at part-load, or low pressure ratios, and which can be properly controlled in the precooling mode, and 2) the need for a multi-zone model-predictive control algorithm that can be implemented through a commercial building automation system (BAS). The first barrier can be overcome by modifying the controls interface in an appropriate variable refrigerant flow (VRF) chiller to receive high-level logic commands from a supervisory control algorithm. These modifications will allow operation at a specified load schedule, where compressor speed and condenser (or cooling tower) air flow rates are optimized to minimize energy consumption over 24 hours and at each temperature and load condition. The second barrier arises because BASs do not allow complex optimization or model identification methods to be incorporated into building controls. In the foreseeable future, a simplified control algorithm that does not require complicated optimization solvers is needed to demonstrate low-lift cooling systems. This research addresses these barriers through the following four tasks:

- Task 1: Simplify and Refine Predictive Control Algorithms

- Task 2: Develop Prototype Low-Lift Chiller Controller

- Task 3: Test Predictive Control Implementation in Off-the-Shelf Controller

- Task 4: Develop a Field Test Plan.

In Task 1, the control algorithms developed by Armstrong et al (2009a,b) and Gayeski (2010) are expanded to include all expected loads in a typical multi-zone TABS building and simplified to exclude complex optimization solvers so that they can be readily implemented in a BAS. In Task 2, a prototype low-lift chiller controller is designed and fabricated to operate a commercially available chiller at low pressure ratios with supervisory commands from a BAS. In Task 3, an off-the-shelf supervisory controller is used accept commands from the building controls virtual test bed (BCVTB) and to communicate commands to the prototype low-lift chiller controller. Finally, in Task 4, opportunities for a field demonstration of low-lift cooling and current design options are reviewed.

Use of specific tradenames and companies within this document are for research purposes only and do not constitute and endorsement of these items. 


\section{Nomenclature}

\begin{tabular}{|c|c|}
\hline BAS & Building automation system \\
\hline BCVTB & Building control virtual test bed \\
\hline COP & Coefficient of performance \\
\hline CRTF & Comprehensive room transfer function \\
\hline CTF & Conduction transfer function \\
\hline $\mathrm{d}_{\mathrm{j}, \mathrm{k}}$ & Diffuse solar load transfer function coefficient for zone $\mathrm{j}$ at time lag $\mathrm{k}$ \\
\hline dll & Dynamically linked library \\
\hline $\mathrm{D}_{\mathrm{j}, \mathrm{k}}$ & Direct solar load transfer function coefficient for zone $\mathrm{j}$ at time lag $\mathrm{k}$ \\
\hline DOAS & Dedicated outdoor air system \\
\hline DV & Dependent variable \\
\hline EIR & Energy input ratio \\
\hline $\mathrm{f}$ & Condenser fan speed \\
\hline GPIC & Greater Philadelphia Innovation Cluster \\
\hline GPS & Generalized pattern search \\
\hline HVAC & Heating, ventilation and air conditioning \\
\hline$i_{j, k}$ & Internal heat rate transfer function coefficient for zone $\mathrm{j}$ at time lag $\mathrm{k}$ \\
\hline IPM & Intelligent power module \\
\hline j & The index for a particular thermal zone $\mathrm{j}$ in a building \\
\hline K & The index for the next timestep being predicted \\
\hline $\mathrm{k}$ & $\begin{array}{l}\text { Lag index for a coefficient that represents the contribution of a time series } \\
\text { variable, } T, Q \text {, D or } d, k \text { steps back in time }\end{array}$ \\
\hline LEED & Leadership in Energy and Environmental Design \\
\hline LLCS & Low-lift cooling systems \\
\hline $\mathrm{m}_{\mathrm{jp}, \mathrm{k}}$ & $\begin{array}{l}\text { Mechanical system heat rate transfer function coefficient for zone j from } \\
\text { mechanical system "p" at time lag " } k \text { " }\end{array}$ \\
\hline$\dot{\mathrm{m}}_{\mathrm{chw}, \mathrm{zj}}$ & Chilled-water mass flow rate for zone $\mathrm{j}$ \\
\hline$\dot{\mathrm{m}}_{\mathrm{chw}}$ & Total chilled-water mass flow rate (sum of zone flows) \\
\hline $\mathrm{N}$ & The order of the multi-zone CRTF model \\
\hline $\begin{array}{l}\mathrm{O}_{\mathrm{jz}, \mathrm{k}} \\
\operatorname{lag} \mathrm{k}\end{array}$ & Operative temperature transfer function coefficient for zone $\mathrm{j}$ from zone $\mathrm{z}$ at time \\
\hline $\mathrm{p}_{\mathrm{j}, \mathrm{k}}$ & Occupant (people) heat rate transfer function coefficient for zone $\mathrm{j}$ at time lag $\mathrm{k}$ \\
\hline P & Condensing unit power consumption \\
\hline$P_{c h}$ & Chiller power consumption \\
\hline$P_{\mathrm{ch}, \tau}$ & Chiller power consumption at time $\tau$ \\
\hline$P_{e, \tau}$ & Evaporating temperature penalty at time $\tau$ \\
\hline$P_{0, \tau}$ & Operative temperature penalty at time $\tau$ \\
\hline PC & Printed circuit \\
\hline PNNL & Pacific Northwest National Laboratory \\
\hline Q & Condensing unit cooling capacity \\
\hline $\mathrm{Q}_{\mathrm{ij}, \mathrm{k}}$ & Internal electric heat rate to zone $\mathrm{j}$ at time lag $\mathrm{k}$ \\
\hline
\end{tabular}




\begin{tabular}{|c|c|}
\hline $\mathrm{Q}_{\mathrm{m}, \mathrm{k}}$ & The thermal heat rate delivered by the mechanical system at time lag $\mathrm{k}$ \\
\hline $\mathrm{Q}_{\mathrm{pj}, \mathrm{k}}$ & Occupant heat rate to zone $\mathrm{j}$ at time lag $\mathrm{k}$ \\
\hline$Q_{d, k}$ & Diffuse solar heat rate at time lag $\mathrm{k}$ \\
\hline $\mathrm{Q}_{\mathrm{D}, \mathrm{k}}$ & Direct solar heat rate at time lag $\mathrm{k}$ \\
\hline $\mathrm{Q}_{\mathrm{mjp}, \mathrm{k}}$ & $\begin{array}{l}\text { Sensible heating (positive) or cooling (negative) rate from mechanical system } p \text { in } \\
\text { zone } j \text { at time lag } k\end{array}$ \\
\hline $\mathrm{R}$ & Total number of mechanical systems in the zone \\
\hline$\tau$ & Time \\
\hline $\mathrm{T}_{\mathrm{cc}}$ & The concrete-core temperature \\
\hline $\mathrm{T}_{\mathrm{cc}, \mathrm{z}}$ & The concrete-core temperature in zone $\mathrm{z}$ \\
\hline $\mathrm{T}_{\text {chwr,z }}$ & The chilled water return temperature from a chilled water loop in zone $\mathrm{z}$ \\
\hline $\mathrm{T}_{\mathrm{e}}$ & Evaporating temperature \\
\hline $\mathrm{T}_{\mathrm{e}, \mathrm{min}}$ & Minimum allowed chiller evaporating temperature \\
\hline $\mathrm{T}_{\mathrm{oj}, \mathrm{k}}$ & Operative temperature of zone $\mathrm{j}$ at time lag $\mathrm{k}$ \\
\hline $\mathrm{T}_{\mathrm{o}, \min , \tau}$ & Minimum allowed zone operative temperature at time $\tau$ \\
\hline $\mathrm{T}_{\mathrm{o}, \max , \tau}$ & Maximum allowed zone operative temperature at time $\tau$ \\
\hline $\mathrm{T}_{\text {chwr,zj }}$ & Chilled-water return temperature from zone $\mathrm{j}$ \\
\hline $\mathrm{T}_{\text {chwr }}$ & Chilled-water return temperature to the chiller \\
\hline $\mathrm{T}_{\text {chws }}$ & Chilled-water supply temperature from the chiller to all zones \\
\hline $\mathrm{T}_{\mathrm{ccj}, \mathrm{k}}$ & Concrete-core temperature of the TABS in zone $\mathrm{j}$ at time lag $\mathrm{k}$ \\
\hline $\mathrm{T}_{\mathrm{o}}$ & Operative temperature of the zone \\
\hline $\mathrm{T}_{\mathrm{x}}$ & Outdoor air temperature \\
\hline $\mathrm{T}_{\mathrm{x}, \mathrm{k}}$ & Exterior climate temperature at time lag $\mathrm{k}$ \\
\hline TABS & Thermo-active building systems \\
\hline TES & Thermal energy storage \\
\hline VRF & Variable refrigerant flow \\
\hline $\mathrm{x}_{\mathrm{j}, \mathrm{k}}$ & External climate temperature transfer function coefficient for zone $\mathrm{j}$ at time lag $\mathrm{k}$ \\
\hline $\mathrm{Z}$ & Total number of zones in the building \\
\hline$\kappa_{\mathrm{j}, \mathrm{k}}$ & $\begin{array}{l}\text { Concrete-core temperature transfer function coefficient for TABS in zone } \mathrm{j} \text { at } \\
\text { time lag } \mathrm{k}\end{array}$ \\
\hline$\gamma$ & Operative temperature penalty constant in $\mathrm{kW} /{ }^{\circ} \mathrm{C}$ \\
\hline$\sigma_{\mathrm{j}, \mathrm{k}}$ & $\begin{array}{l}\text { Operative temperature transfer function coefficient for TABS in zone } \mathrm{j} \text { at time lag } \\
\mathrm{k}\end{array}$ \\
\hline$\varphi_{\mathrm{j}, \mathrm{k}}$ & Internal heat rate transfer function coefficient for TABS in zone $\mathrm{j}$ at time lag $\mathrm{k}$ \\
\hline$\rho_{\mathrm{j}, \mathrm{k}}$ & $\begin{array}{l}\text { Occupant (people) heat rate transfer function coefficient for TABS in zone } \mathrm{j} \text { at } \\
\text { time lag } \mathrm{k}\end{array}$ \\
\hline$\delta_{\mathrm{j}, \mathrm{k}}$ & Diffuse solar load transfer function coefficient for TABS in zone $\mathrm{j}$ at time lag $\mathrm{k}$ \\
\hline$\chi_{\mathrm{j}, \mathrm{k}}$ & Direct solar load transfer function coefficient for TABS in zone $\mathrm{j}$ at time lag $\mathrm{k}$ \\
\hline$\omega_{\mathrm{c}}$ & Chiller compressor speed \\
\hline$\varpi_{\text {pump }}$ & Vector of zone chilled-water pump speeds \\
\hline
\end{tabular}




\section{Contents}

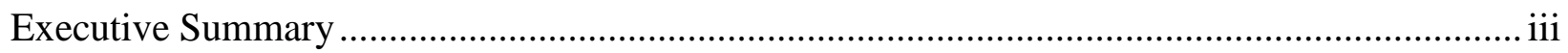

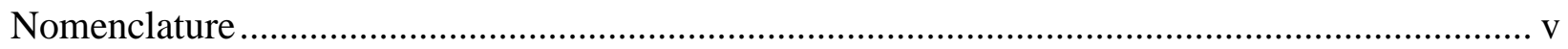

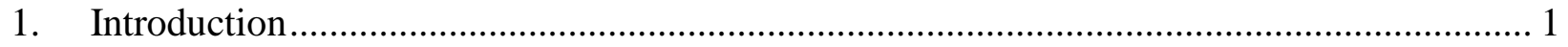

2. Low-Lift Cooling System Control Algorithm ................................................................... 5

2.1 Data-Driven Modeling of Multi-zone Buildings with Low-lift Cooling Systems ............ 5

2.2 Multi-zone Low-lift Cooling Model-predictive Control Optimization............................ 10

2.3 Simplified Low-lift Cooling Model-predictive Control Algorithm ................................. 11

2.4 Summary of Low-lift Cooling Model-predictive Control Algorithm ............................. 16

3. Prototype Low-Lift Chiller Controller.............................................................................. 17

3.1 Chiller Component Control.................................................................................. 18

3.2 Low-lift Chiller Controller Design and Fabrication.......................................................... 19

3.3 Low-lift Chiller Performance Curve .......................................................................... 20

3.4 Summary of Low-lift Chiller Controller Development..................................................... 21

4. Low-lift Control through a Commercial BAS ………....................................................... 23

5. Low-Lift Cooling Field Test Opportunities ...................................................................... 27

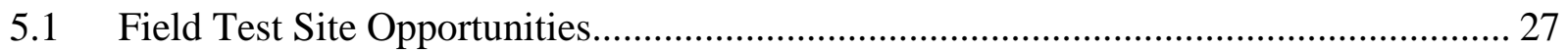

5.1.1 Greater Philadelphia Innovation Cluster (GPIC) Hub for Energy Efficient

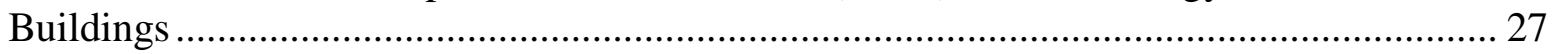

5.1.2 Collaboration with the Masdar Institute of Science and Technology ..................... 27

5.1.3 CEMEX San Bernabos Community Center in Monterrey, Mexico ....................... 28

5.1.4 Field Test in Collaboration with Shine Engineering and EVCO Mechanical ........ 28

$5.2 \quad$ Field Test Site Design Concept ................................................................................. 28

5.3 Low-lift Cooling Target Market............................................................................. 28

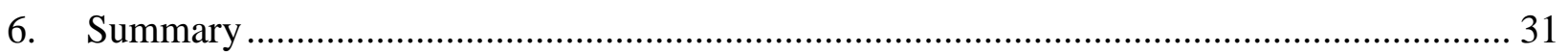

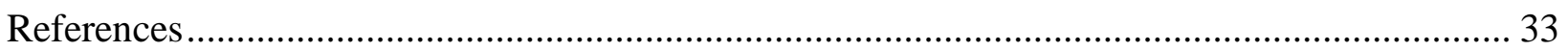




\section{Figures}

Figure 1. EIR (reciprocal of coefficient of performance - COP) for each hour of the prediction horizon as a function of cooling rate.

Figure 2. Bounding instantaneous cooling load profiles (left) and corresponding TABS-shifted precooling rate profiles (right)..... 13

Figure 3. Contour map of possible EIR at each cooling rate for every hour of the day superimposed with the maximum and minimum instantaneous cooling load profiles (dotted lines), TABS-shifted precooling rate profiles (solid black lines), and simplified optimal precooling rate schedule (solid red line)

Figure 4. Optimal cooling rate (left) and EIR (right) at each hour of the day within the allowed region of operation (color map)

Figure 5. Cumulative cooling load for a given maximum EIR (left), optimal cumulative precooling rate at each hour of the day (center) and optimal chiller power consumption at each

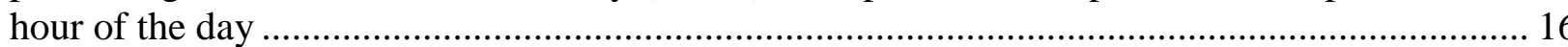

Figure 6. Rolling-piston compressor condensing unit .............................................................. 18

Figure 7. Evaluation condenser fan controller board ................................................................. 18

Figure 8. Compressor controller test bench and early control board prototype............................ 19

Figure 9. Prototype control board design and fabricated board.................................................... 20

Figure 10. BCVTB simulation for low-lift cooling model identification................................... 23

Figure 11. BCVTB simulation for simplified low-lift control implementation through the NCE25 to the prototype chiller controller …………………..................................................... 24

Figure 12. Compressor speed (left) and condenser fan speed (right) point trending in the NCE25 BAS controller, receiving commands over BACnet from the low-lift control algorithm

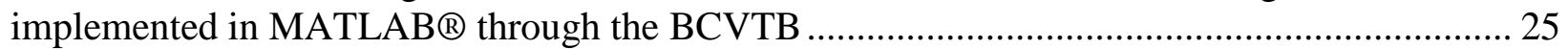

Figure 13. Masdar Institute low-lift cooling field test site progress ............................................. 27 


\section{Tables}

Table 1. Chiller performance curve coefficients for $\mathrm{T}$ given in ${ }^{\circ} \mathrm{C}, \omega$ given in $\mathrm{Hz}$ and $\mathrm{f}$ given in

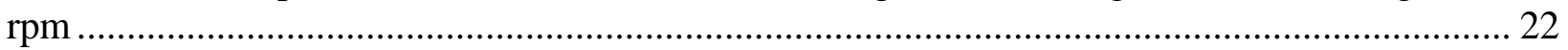




\section{Introduction}

KGS Building LLC (KGS) and Pacific Northwest National Laboratory (PNNL) have developed simplified model-predictive low-lift cooling control algorithms and a prototype a low-lift chiller controller. The algorithms have been implemented and tested through a commercial building automation system (BAS) controller and opportunities for a demonstration of low-lift cooling systems have been identified. Low-lift cooling is a highly efficient cooling strategy conceived to enable low or net-zero energy buildings (Armstrong et al. 2009a,b). A low-lift cooling system consists of a high efficiency low-lift chiller, radiant cooling, thermal storage, and modelpredictive control to pre-cool thermal storage overnight.

An effective design approach for low-lift cooling is to use building integral thermal mass for thermal storage. This can be accomplished with thermo-active building systems (TABS), where pipe is embedded in concrete to allow for active charging of building thermal mass. This approach can be applied easily to new construction, or to existing buildings undergoing a deep retrofit, where a thin "topping” slab can be applied to existing infrastructure. The ultimate goal of this program is to develop commercially implementable low-lift cooling system that can meet the high cooling energy savings potential shown to exist across many climate zones and building types (Jiang et al. 2007, Armstrong et al. 2009a,b, Katipamula et al. 2010).

The present work addresses two barriers to achieving commercially viable low-lift cooling systems, the lack of low-lift chillers that operate at sufficiently low pressure ratios and allow optimal model-predictive supervisory control, and the need for a simple control algorithm that can be implemented through a commercial BAS. The first barrier can be overcome by modifying a chiller with an appropriate compressor to operate at very low pressure ratios and to receive high-level logic commands from a supervisory control algorithm. These modifications will allow operation at a specified load schedule, where compressor speed and condenser flow rates are optimized to minimize energy consumption over 24 hours and at each temperature and load condition.

The second barrier arises because BASs do not allow complex optimization or model identification methods to be incorporated into building controls. In the foreseeable future, a simplified control algorithm that does not require complicated optimization solvers is needed to demonstrate low-lift cooling systems.

This research addresses these barriers through the following four tasks:

- $\quad$ Task 1: Simplify and Refine Predictive Control Algorithms

- Task 2: Develop Prototype Low-Lift Chiller Controller

- Task 3: Test Predictive Control Implementation in Off-the-Shelf Controller

- Task 4: Develop a Field Test Plan.

In Task 1, the control algorithms developed by Armstrong et al. (2009a,b) and Gayeski (2010) are expanded to include all expected loads in a typical multi-zone building and simplified to exclude complex optimization solvers so that they can be readily implemented in building control systems. The simplified predictive pre-cooling control algorithm includes predictions of 
thermal load including solar, occupancy, internal, and temperature-driven loads for a multi-zone low-lift cooling system. Furthermore, the algorithm has been simplified to allow for implementation in a BAS using simple look up tables and conventional math functions.

In Task 2, a prototype low-lift chiller controller is designed and fabricated to operate a commercially available chiller at low pressure ratios with supervisory commands from a BAS. Existing variable capacity chiller and heat pump technologies do not have the required control functionality to accommodate low-lift cooling equipment. They respond to thermostatic controls with fixed internal control algorithms. To overcome these barriers, Redwire, LLC, in collaboration with KGS Buildings, designed, fabricated and tested a low-lift chiller control board that can control commercially available condensing units. Condensing units with rolling-piston compressors and high-turndown, highly efficient variable-speed motors were selected suitable for operation at very low pressure ratios. The prototype controller can accept commands wirelessly or over RS-485 communication protocol from any BAS controller.

In Task 3, an off-the -shelf supervisory BAS controller is used to communicate commands to the prototype low-lift chiller controller determined by the simplified low-lift model-predictive control algorithm. To simulate the operation of a low-lift cooling system in a real building, an EnergyPlus simulation is used to model the zone temperature response of a building with a concrete core radiant floor using the low-temperature radiant system model. This EnergyPlus simulation does not have suitable capabilities to model a receding horizon model-predictive control algorithm in which a chiller is controlled at each hour to pre-cool a TABS concrete-core radiant floor.

To test the low-lift control algorithm and the model identification methods required to identify a zone temperature response model from real building data, a transfer function model is identified from the EnergyPlus model, which may be used to simulate the response of the zone and TABS to cooling inputs determined by the low-lift control algorithm. Identification of a building model and simulation of the building response are performed in MATLAB ${ }^{\circledR}$. The simplified modelpredictive control algorithm, which includes only lookup tables for chiller performance and conventional math functions to determine zone response, is implemented either in an external program (such as a cloud-based computational service), on the BAS controller, or embedded on the chiller controller. For purposes of this research, the control algorithm is implemented in MATLAB ${ }^{\circledR}$ and commands are sent to the BAS controller via BACnet through the building control virtual test bed (BCVTB). The BAS controller sends commands to the prototype chiller control board to control the commercial condensing unit under model-predictive control.

Finally, in Task 4, KGS Buildings and PNNL have pursued opportunities for a field demonstration of low-lift cooling, and created preliminary design options. These options are suitable for both new construction or select renovation projects, where there is a possibility to incorporate thermo-active building slabs in an existing building. This can be accomplished using a topping slab, where concrete may be poured on existing floor slabs with embedded chilledwater piping. Currently, the best options for a field test include the Greater Philadelphia Innovation Cluster (GPIC) Hub, collaboration with the Masdar Institute of Science and Technology, a joint project with CEMEX, a global building materials company, and private 
projects in collaboration with EVCO Mechanical and Shine Engineering, mechanical service and engineering firms in the New York/New Jersey market.. 


\section{Low-Lift Cooling System Control Algorithm}

Developing a low-lift cooling system control algorithm suitable for a field test requires accommodating all loads in a multi-zone TABS building with low-lift cooling and simplifying that algorithm for implementation through a commercial BAS. In this section, the data-driven building temperature response models presented by Armstrong et al. (2009a, b), Gayeski (2010), and Gayeski et al. (2011b) were adapted to simplify occupancy load estimates with simple sensor measurement requirements. Furthermore, the resulting multi-zone low-lift cooling control algorithm is simplified to avoid the need for complex optimization solvers that will not be available in a typical BAS. Ultimately, the simplified control algorithm may be incorporated into building control, either by programming it directly in a BAS, embedding the control on a low-lift chiller control board, or remotely performing supervisory control functions through a separate supervisory control system interfacing with the BAS, such as the research-oriented BCVTB or a cloud-based supervisory control platform.

The first part of this section will describe how the modeling methods developed in previous work have been refined to be applicable to multi-zone buildings with the full range of thermal loads and zone diversity. The second part will describe how to implement the rigorous modelpredictive algorithm in the case where an optimization solver is available. The third part of this section will describe a simplified control algorithm that avoids the need for an optimization solver by bracketing the allowable cooling rates to meet comfort conditions and meet the load most efficiently by delivering the total daily load at the lowest possible average energy input ratio (EIR) within the allowed operation region.

\subsection{Data-Driven Modeling of Multi-zone Buildings with Low-lift Cooling Systems}

The operative temperature of each zone in a building changes based on the temperatures of adjacent zones (such as other spaces of the building or the outside conditions) and thermal inputs to the zone (such as internal loads [lights, plugs, occupants], solar loads, or mechanical system heating and cooling rates). A data-driven model of building temperature response is required that can be identified from conventional BAS sensor inputs, weather, and measured or estimated internal loads. The resulting model can then be used to predict zone temperatures throughout the building by driving it with forecast weather and internal loads and any hypothetical sequence of control actions.

In a single-zone building with a single heating, ventilation and air conditioning (HVAC) system, the operative temperature of the zone, $\mathrm{T}_{0}$, can be predicted from a specific type of transferfunction model, called a comprehensive room transfer function (CRTF), of the following form:

$$
T_{o, k}=\sum_{k=K-N}^{K-1} o_{k} T_{o, k}+\sum_{k=K-N}^{K} x_{k} T_{x, k}+\sum_{k=K-N}^{K} i_{k} Q_{i, k}+\sum_{k=K-N}^{K} p_{k} Q_{p, k}+\sum_{k=K-N}^{K} d_{k} Q_{d, k}+\sum_{k=K-N}^{K} D_{k} Q_{D, k}+\sum_{k=K-N}^{K} m_{k} Q_{m, k}
$$

The operative temperature of a single zone at time $\mathrm{K}$ (see report nomenclature for definition of the symbols) can be predicted from measured values of its past operative temperature, and measured and predicted values of external climate temperature and thermal loads, including internal loads, occupant loads, diffuse and direct solar loads, and mechanical system loads. 
A few changes and additions to equation (1) are required to make it applicable to a complete low-lift cooling system in a multi-zone building. In low-lift cooling, latent loads are met using a dedicated outdoor air system (DOAS) with efficient dehumidification, such that the relative humidity of the zone is kept low enough to prevent condensation on the cold surface of the radiant cooling system and maintain comfort. To account for the sensible cooling rate delivered by the DOAS, multiple mechanical systems may be included in the temperature response model.

Furthermore, low-lift cooling may be applied to multi-zone buildings in which different internal loads, mechanical heating or cooling, and operative temperatures may exist in each zone. A refined temperature response model that includes multiple zones (three are used as an example) and the effect of the DOAS by allowing for an arbitrary number of mechanical systems in each zone may be written as follows:

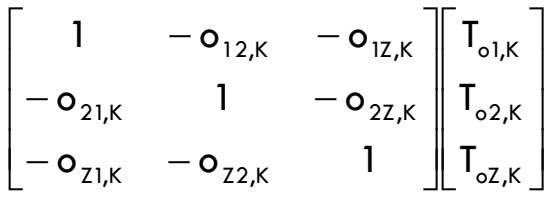

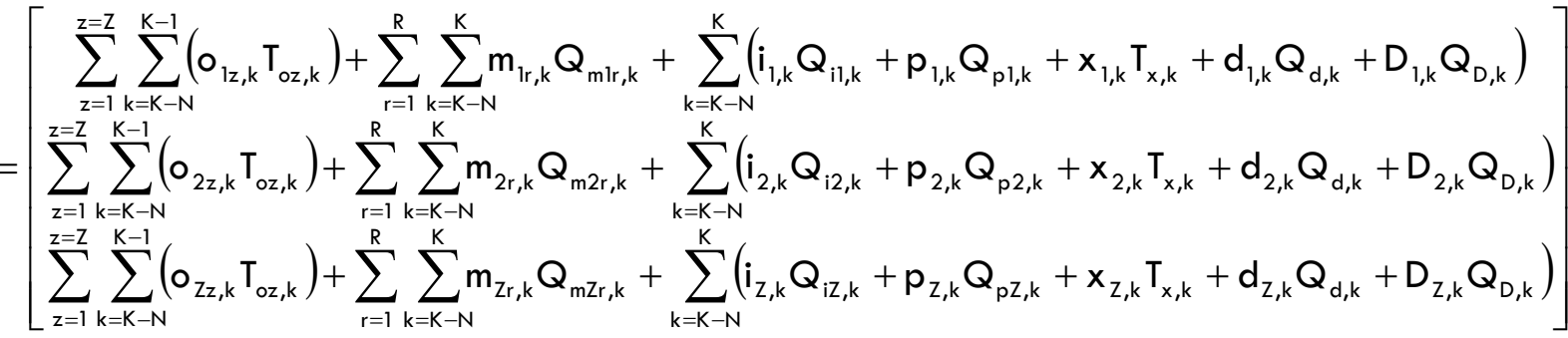

where, similar to equation (1), the operative temperatures at the next timestep $\mathrm{K}$ are predicted from measured values of past operative temperatures along with measured and forecast values of external climate temperature and relevant thermal loads. In this case, mechanical system loads are included from R mechanical systems, which might include the DOAS, and operative temperatures are predicted for $\mathrm{Z}$ zones. The equation can be used to predict zone operative temperatures $\mathrm{T}_{\mathrm{oj}, \mathrm{k}}$ for each zone $\mathrm{j}$.

At steady state, with no thermal loads and all temperatures equivalent, constraints on the coefficients of equation (2) are apparent, consistent with Armstrong et al. (2006a,b). These constraints are given by the following equation for all zones $\mathrm{j}$, where $\mathrm{o}_{\mathrm{jj}, \mathrm{K}}=-1$ for all zones:

$$
\sum_{z=1}^{z=Z} \sum_{k=K-N}^{K} o_{i z, k}+\sum_{k=K-N}^{K} x_{i, k}=0
$$

The prediction of zone operative temperatures presented above provides only part of the information (the thermal comfort conditions) required to implement model-predictive control of low-lift chillers. The other information required for model-predictive control in low-lift cooling is a model of the power consumption of the low-lift chiller. Physics-based models of low-lift chillers have been presented in Armstrong et al. (2009a, b) and Zakula et al. (2011), which require information about the chiller compressor speed, condenser flow rate, evaporator flow 
rate, condenser fluid entering temperature, and evaporator fluid entering temperature to predict low-lift chiller cooling capacity and power consumption. For a given cooling rate, external climate temperature (which is equivalent to the condenser air entering temperature for an aircooled chiller), and chilled-water return temperature (which is equivalent to evaporator fluid entering temperature), there is an optimal combination of compressor speed, condenser fan speed and evaporator flow rate to meet the desired cooling rate that minimizes chiller power consumption.

Predictions of external climate temperature $T_{x}$ and chilled-water return temperature $T_{\text {chwr }}$ are required to minimize chiller energy consumption by optimizing chiller compressor speed and condenser and evaporator flow rates. If an optimization is to be performed over a 24-hour horizon, then predictions of these temperatures are required for the next 24 hours. In the context where building thermal mass provides thermal energy storage through a radiant concrete structure (such as a TABS), the chilled-water return temperature depends on the thermal state of the TABS thermal energy storage (TES). An internal concrete-core temperature can be measured, $\mathrm{T}_{\mathrm{cc}}$, to represent the thermal state of the TABS-TES. Future values of $\mathrm{T}_{\mathrm{cc}}$ must also be predicted, along with zone operative temperatures, to predict $\mathrm{T}_{\mathrm{chwr}}$, evaporating temperature $\mathrm{T}_{\mathrm{e}}$, and ultimately chiller power consumption $\mathrm{P}_{\mathrm{ch}}$. To predict $\mathrm{T}_{\mathrm{cc}}, \mathrm{T}_{\mathrm{chwr}}, \mathrm{T}_{\mathrm{e}}$, and $\mathrm{P}_{\mathrm{ch}}$, additional data-driven models of building thermal response are required.

The TABS-TES system can be treated as an Nth order thermal model, similar to the building zones, but with fewer thermal inputs. The TABS-TES system inputs include the operative temperatures on either side of the concrete slab and any radiant thermal loads impinging directly onto the surfaces of the slab from internal or solar loads. The resulting transfer function representation of concrete-core temperature response is as follows:

$$
\left[\begin{array}{l}
T_{c c 1, K} \\
T_{c c 2, K} \\
T_{c c Z, K}
\end{array}\right]=\left[\begin{array}{c}
\sum_{k=K-N}^{K-1}\left(\kappa_{1, k} T_{c c 1, k}\right)+\sum_{k=K-N}^{K-1}\left(\sigma_{11, k} T_{o 1, k}\right)+\sum_{k=K-N}^{K}\left(\varphi_{1, k} Q_{i 1, k}+\rho_{1, k} Q_{p 1, k}+\delta_{1, k} Q_{d, k}+\chi_{1, k} Q_{D, k}+m_{1, k} Q_{m 1, k}\right) \\
\sum_{k=K-N}^{K-1}\left(\kappa_{2, k} T_{c c 2, k}\right)+\sum_{k=K-N}^{K-1}\left(\sigma_{22, k} T_{o 2, k}\right)+\sum_{k=K-N}^{K}\left(\varphi_{2, k} Q_{i 2, k}+\rho_{2, k} Q_{p 2, k}+\delta_{2, k} Q_{d, k}+\chi_{2, k} Q_{D, k}+m_{2, k} Q_{m 2, k}\right) \\
\sum_{k=K-N}^{K-1}\left(\kappa_{Z, k} T_{c c Z, k}\right)+\sum_{k=K-N}^{K-1}\left(\sigma_{Z Z, k} T_{o Z, k}\right)+\sum_{k=K-N}^{K}\left(\varphi_{Z, k} Q_{i Z, k}+\rho_{Z, k} Q_{p Z, k}+\delta_{Z, k} Q_{d, k}+\chi_{Z, k} Q_{D, k}+m_{Z, k} Q_{m Z, k}\right)
\end{array}\right]
$$

At steady state, the constraints on the coefficients are as follows (similar to equation (3):

$$
\sum_{z=1}^{z=A i} \sum_{k=K-N}^{K} \sigma_{i z, k}+\sum_{k=K-N}^{K} \kappa_{i, k}=0
$$

The coefficients of equations (2) and (4) can be identified from training data collected from sensors installed in a building. For example,

- globe temperature sensors may be employed to measure operative temperature,

- thermistors may be installed in the TABS to measure concrete-core temperature, 
- internal loads can be estimated from measurements of electrical consumption in each zone and zone occupancy sensor,

- solar loads can be measured through irradiance sensors measuring diffuse and direct solar components ${ }^{\mathrm{a}}$, and

- mechanical system heating and cooling rates can be measured using flow and temperature measurements or estimated using models of system performance as a function of controlled variables.

The chilled-water return temperature to the chiller evaporator, $\mathrm{T}_{\text {chwr }}$, is now needed to estimate evaporating temperature $T_{e}$ and chiller power consumption $P_{c h}$. The evaporator return water is a mixture of the chilled-water returned from each zone in a TABS and, neglecting pipe losses, can be calculated as follows:

$$
\mathrm{T}_{\mathrm{chwr}}=\frac{\sum_{\mathrm{z}=1}^{\mathrm{z}} \mathrm{c}_{\mathrm{p}} \dot{\mathrm{m}}_{\mathrm{chw}, \mathrm{z}} \mathrm{T}_{\mathrm{chwr}, \mathrm{z}}}{\mathrm{c}_{\mathrm{p}} \sum_{\mathrm{z}=1}^{\mathrm{z}} \dot{\mathrm{m}}_{\mathrm{chw}, \mathrm{z}}}
$$

The chilled-water return temperature from each zone, $T_{\text {chwr, }}$ can be calculated using a quasisteady state representation of the concrete-core system as a heat exchanger with a uniform temperature $\mathrm{T}_{\mathrm{cc}, \mathrm{z}}$, calculated using equation (4) for a given cooling rate. At quasi-steady state, the following engineering relation for heat exchanger effectiveness can be applied to the zone TABS (Armstrong et al. 2009a):

$$
\frac{T_{c c, z}-T_{c h w r, z}}{T_{c c, z}-T_{c h w s}}=\exp \left(-\frac{U\left(\dot{m}_{c h w, z}\right) A_{z}}{\dot{m}_{c h w, z} c_{p}}\right)=\varepsilon_{z}\left(\dot{m}_{c h w, z}\right) \text { or } \quad T_{c h w r, z}=T_{c c, z}\left(1-\varepsilon_{z}\left(\dot{m}_{c h w, z}\right)\right)+\varepsilon_{z}\left(\dot{m}_{c h w, z}\right) T_{c h w s}
$$

At the evaporator, ignoring any superheating, a similar heat exchanger equation can be employed to represent the effectiveness of the chiller evaporator:

$$
\frac{T_{c h w s}-T_{e}}{T_{c h w r}-T_{e}}=\exp \left(-\frac{U\left(\dot{m}_{c h w}\right) A_{e}}{\dot{m}_{c h w} c_{p}}\right)=\varepsilon_{e}\left(\dot{m}_{c h w}\right) \quad \text { or } \quad T_{c h w s}=\varepsilon_{e}\left(\dot{m}_{c h w, z}\right) T_{c h w r}+\left(1-\varepsilon_{e}\left(\dot{m}_{c h w, z} z\right) T_{e}\right.
$$

Substituting equation (7) into equation (6) yields the following equation for chilled-water return temperature, where a mixed heat exchanger effectiveness and concrete-core temperature has been defined to simplify the equation:

$$
T_{c h w r}=T_{c h w s} \frac{\sum_{z=1}^{z} c_{p} \dot{m}_{c h w, z} \varepsilon_{z}\left(\dot{m}_{c h w, z}\right)}{\dot{m}_{c h w} c_{p}}+\frac{\sum_{z=1}^{z} c_{p} \dot{m}_{c h w, z}\left(1-\varepsilon_{z}\left(\dot{m}_{c h w, z}\right)\right) T_{c c, z}}{\dot{m}_{c h w} c_{p}} \equiv T_{c h w s} \widetilde{\varepsilon}_{z}+\widetilde{T}_{c c}
$$

\footnotetext{
${ }^{a}$ Using standard or simplified formulas for incident radiation on vertical surfaces with shading
} 
Using equations (8) and (9), the following relation can be found for the chilled-water loop temperature difference:

$$
\mathrm{T}_{\text {chws }}-\mathrm{T}_{\text {chwr }}=\frac{1-\varepsilon_{\mathrm{e}}}{1-\varepsilon_{\mathrm{e}} \widetilde{\varepsilon}_{\mathrm{z}}}\left(\left(1-\widetilde{\varepsilon}_{\mathrm{z}}\right) \mathrm{T}_{\mathrm{e}}-\widetilde{\mathrm{T}}_{\mathrm{cc}}\right)
$$

Furthermore, the total cooling rate delivered by the chiller can be calculated with the following equation:

$Q_{m}=\dot{m}_{c h w} c_{p}\left(T_{c h w s}-T_{c h w r}\right)=\dot{m}_{c h w} c_{p} \frac{1-\varepsilon_{e}}{1-\varepsilon_{e} \widetilde{\varepsilon}_{z}}\left(\left(1-\widetilde{\varepsilon}_{z}\right) T_{e}-\widetilde{T}_{c c}\right)$

The mass flow weighted concrete-core temperature $\widetilde{T}_{c c}$ is still unknown, because the zone concrete-core temperatures $\mathrm{T}_{\mathrm{cc}, \mathrm{z}}$ depend on the chiller cooling rate, which can only be computed once the evaporating temperature $\mathrm{T}_{\mathrm{e}}$ is known. The zone concrete-core temperatures $\mathrm{T}_{\mathrm{cc}, \mathrm{z}}$ must be predicted from zone cooling rates and the other variables in equation (4). One final relation closes the loop between choices of control variables for the low-lift chiller, such as compressor speed, condenser fan speed, and evaporator flow rate (zone pump speeds in a multi-zone TABS), and the temperature response of the building and TABS. From equations (6), (7) and (8), along with the observation that total chiller cooling rate must equal the sum of the zone cooling rates, the following relationship can be found for zone chilled-water return temperatures and the chilled-water supply temperature relative to zone concrete-core temperatures, evaporating temperature, and the total chiller cooling rate.

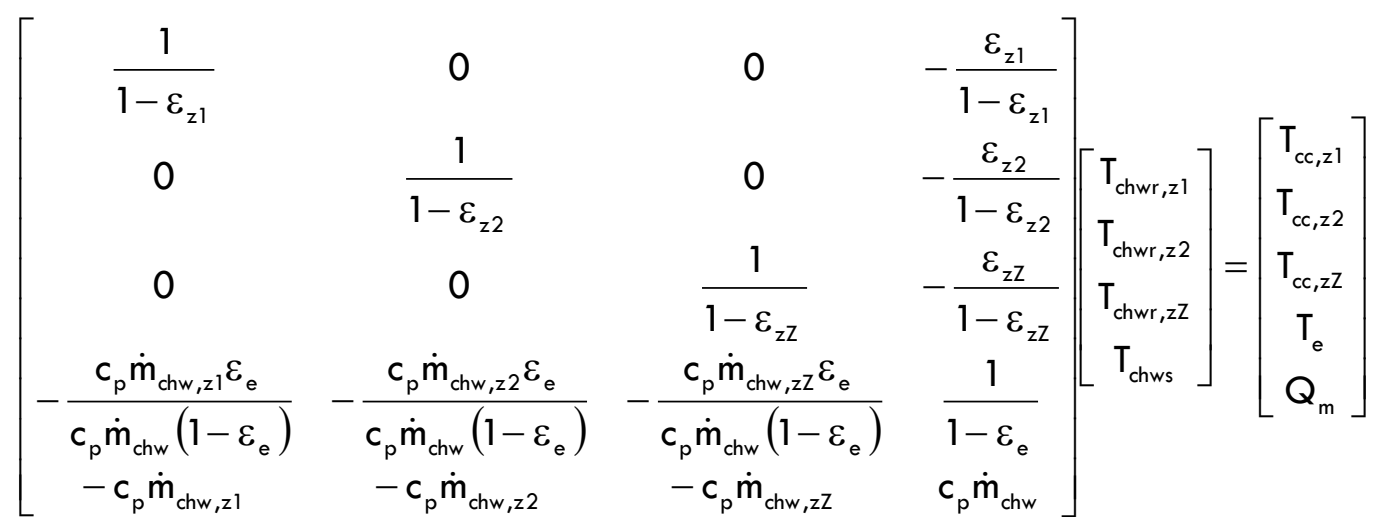

A model of chiller power consumption and cooling capacity is also required, which can be created from measurements (Gayeski et al. 2011a) or physical models (Zakula et al. 2011) and represented by curve-fit performance models:

$$
\begin{aligned}
& P_{c h, k}=f\left(\omega_{c, k}, f_{k}, T_{x, k}, T_{e, K}\right) \\
& Q_{c h, K}=g\left(\omega_{c, k}, f_{k}, T_{x, k}, T_{e, K}\right)
\end{aligned}
$$

In equations (13) and (14), functions $\mathrm{f}$ and g are quad-cubic polynomials for power consumption or cooling capacity at a given time $\mathrm{K}$ as a function of chiller compressor speed, condenser fan 
speed, external climate temperature (condenser air temperature), and evaporating temperature at timestep K. These curves are described in more detail in Section 3.

\subsection{Multi-zone Low-lift Cooling Model-predictive Control Optimization}

To predict the temperature response of the building zones and the power consumption of the chiller at a future timestep $\mathrm{K}$, the following procedure may be followed using the equations above.

1. Select desired chiller compressor speed and zone chilled-water pump speeds. Chilledwater pump speeds determine the zone mass flow rates.

2. Initially, assume an evaporating temperature based on current concrete-core temperatures and total chilled-water mass flow rate.

3. Compute chiller cooling rate and power consumption from equations (13) and (14) using selected compressor speed, forecast external climate temperature, and assumed evaporating temperature from step 2. For a given combination of these variables, there is a fixed optimal condenser fan speed.

4. Assume the zone cooling rates are equivalent to the following:

$$
Q_{z}=\frac{\dot{\mathrm{m}}_{\mathrm{chw}, \mathrm{z}}}{\dot{\mathrm{m}}_{\mathrm{chw}}} Q_{\mathrm{m}}
$$

5. Compute the zone operative temperatures and concrete-core temperatures at the next timestep from equations (2) and (4) using the estimated zone cooling rates from step 4.

6. Compute the zone chilled-water return temperatures and chilled-water supply temperature from equation (12), and compare calculated zone cooling rates with estimated zone cooling rates.

7. Iterate steps 2 through 6 until the assumed zone cooling rates and the evaporating temperature equals the calculated zone cooling rates and evaporating temperature in equation (12).

8. Once the system converges to a solution, the calculated zone operative temperatures and concrete-core temperatures are the predicted temperatures for future timestep K.

For a 24-hour forecast, the procedure is repeated 24 times until the total chiller energy consumption and zone operative temperature response have been computed for each of the next 24 hours for a given schedule of hourly chiller compressor speeds and zone chilled-water pump speeds. An optimization function that penalizes chiller power consumption, deviations of zone operative temperatures from thermal comfort constraints, and chiller evaporating temperatures that approach freezing can be expressed as follows:

$$
\operatorname{argmin}_{\omega_{c}, \vec{\omega}_{\mathrm{pump}, \tau}} \mathrm{J}=\sum_{\tau=1}^{24} \mathrm{P}_{\mathrm{ch}, \tau}+\mathrm{P}_{\mathrm{o}, \tau}+\mathrm{P}_{\mathrm{e}, \tau}
$$

where $\mathrm{P}_{c h, \tau}$ is the chiller power consumption at time $\tau, \mathrm{P}_{\mathrm{o}, \tau}$ is the operative temperature penalty at time $\tau$, and $\mathrm{P}_{\mathrm{e}, \tau}$ is the evaporating temperature penalty at time $\tau$. The chiller power consumption, zone operative temperatures and chiller evaporating temperature at each timestep can be computed by following the procedures described above using equations (2) through (15). The 
operative temperature penalty and evaporating temperature penalty are computed from the following equations:

$$
\begin{aligned}
& P_{o, \tau}=\sum_{z=1}^{z}\left\{\begin{array}{cc}
T_{o z, \tau}>T_{o, \max , \tau} & \gamma\left(T_{o, \min , \tau}-T_{o z, \tau}\right) \\
T_{o, \min , \tau}<T_{o z, \tau}<T_{o, \max , \tau} & 0 \\
T_{o z, \tau}<T_{o, \min , \tau} & \gamma\left(T_{o z, \tau}-T_{o, \max , \tau}\right)
\end{array}\right. \\
& P_{e, \tau}=\left\{\begin{array}{l}
T_{e}>T_{e, \min } 0 \\
T_{e}<T_{e, \min } \text { INF }
\end{array}\right.
\end{aligned}
$$

The optimal set of control variables for the low-lift system is identified by minimizing equation (16) with a specific optimization algorithm. Currently, a generalized pattern search (GPS) algorithm is being used to find the optimal solution, consistent with that presented in Gayeski (2010) and Gayeski et al. (2011b). The control variables to be optimized include 24 compressor speeds, one for each of the 24 hours of the forecast, and 24 times $Z$ chilled-water pump speeds, one for each zone at each of the 24 hours. The optimization problem is thus a 24 times $(1+\mathrm{Z})$ dimensional problem.

\subsection{Simplified Low-lift Cooling Model-predictive Control Algorithm}

The previous section described a rigorous mathematical formulation of the low-lift cooling model-predictive control optimization problem and the required data-driven models of building and TABS temperature response. A simplified approach is desired that is less computationally intensive, particularly one that does not require an optimization solver, and is thus more suitable for integration in an embedded chiller controller or through a commercial BAS. Even if a BAS supports basic optimization methods, a simplified control algorithm will increase the speed at which the optimization can be performed, making it more suitable for real-time optimization. This section describes a simplified method for implementing model-predictive control of low-lift cooling systems.

The first strategy for simplifying low-lift cooling control is to separate the model-predictive control optimization, where the optimal cooling rates at each hour of the next 24 hours are predicted, from the static chiller optimization, where the condenser fan speed, compressor speed, and evaporator flow rate, or chilled-water pump speed(s), are optimized to meet a given cooling load at a particular time. Unfortunately, in a low-lift cooling system with TABS, the choice of chilled-water pump speed at any given hour affects the optimal choice of chilled-water pump speed at any future hour because it affects the concrete-core temperature response and subsequently the allowable evaporating temperature of the chiller. This in turn affects the chiller efficiency at future hours. This complication seemingly prevents decoupling of the static chiller control optimization from the model-predictive control optimization.

However, in a well-designed TABS, the concrete-core temperatures, and thus chilled-water return temperature should not vary by more than a few degrees over the course of the day as the slab cools down. By neglecting the impact of chilled-water return temperature on evaporating temperature and assuming a constant or slightly decreasing chilled-water return temperature over 
the course of the day (which may vary with cooling rate), the more significant terms of outdoor air temperature and part-load fraction can be dealt with separately in a model-predictive control optimization. The secondary static optimization of compressor speed, condenser fan speed, and chilled-water pump speed can then be performed at each timestep to determine the most efficient way to meet the loads determined by the model-predictive control algorithm. The modelpredictive control optimization can be decoupled from the static optimization of pump, fan and compressor speeds at a given operation condition by neglecting variation of chilled water return temperature, accounting only for the more significant impacts of outdoor air temperature and part-load ratio.

Utilizing this assumption, the EIR as a function of forecast outdoor air temperature and possible cooling rates can be assembled into a chiller performance lookup table, describing chiller EIR as a function of outdoor air temperature, cooling rate or part-load fraction, and evaporating temperature. A typical daily performance table that provides the optimal static chiller EIR as a function of cooling rate and time of day is plotted below in Figure 1. The x-axis is the hour of the day, the $y$-axis is the cooling rate delivered at each hour, and the z-axis is the EIR at each hour for a given cooling rate. The variation in achievable EIR at each hour results from the diurnal temperature variation.

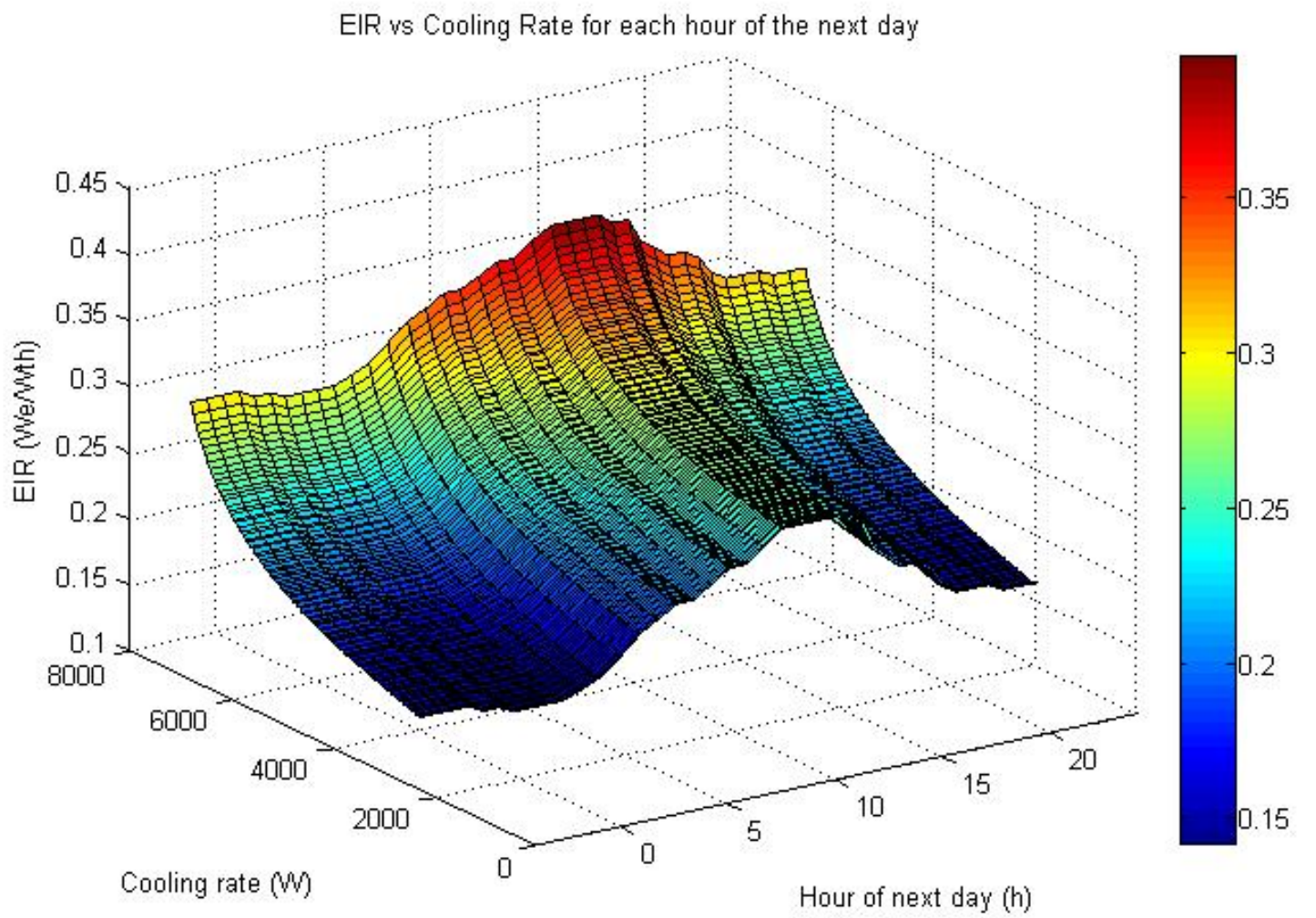

Figure 1. EIR (reciprocal of coefficient of performance - COP) for each hour of the prediction horizon as a function of cooling rate 
The thermal comfort constraints on each zone can also be simplified. In the rigorous control algorithm, the zone operative temperature trajectories are calculated for each candidate concretecore hourly precooling rate schedule. The resulting temperature trajectories are penalized for excursions from the allowed comfort region. In the simplified approach, upper bounds on the hourly cooling rates and lower bounds on the total precooling delivered through each hour are determined, within which comfort conditions are met, based on the minimum and maximum comfortable temperature in the zone. This is accomplished by first calculating the instantaneous cooling load at each hour required to meet an upper operative temperature constraint and a lower operative temperature constraint. These instantaneous load schedules can be calculated using conventional multi-zone CRTF models identified from building data. Once these upper and lower bound load schedules have been determined, they can be converted to a concrete-core precooling rate schedule using transfer function coefficients for both the instantaneous cooling loads and concrete core precooling rate schedule in the CRTF functions. This conversion shifts the chiller loads to earlier in the day and flattens out its peaks, as shown in Figure 2. The TABS can be designed to shift typical load profiles throughout the cooling season to an appropriate distribution, e.g., so the precooling rate peaks occur at the same hour as the typical cooling season minimum daily outdoor temperature.
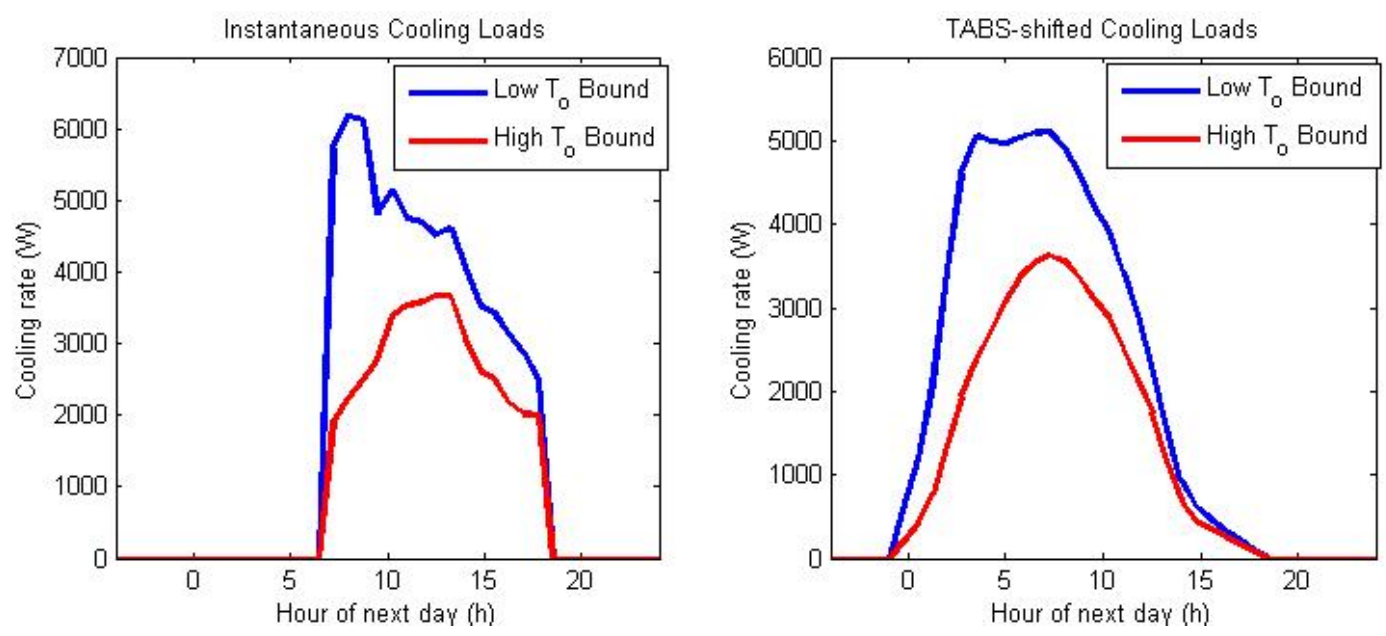

Figure 2. Bounding instantaneous cooling load profiles (left) and corresponding TABS-shifted precooling rate profiles (right)

Any concrete-core precooling rate schedule below the blue load profile on the right will not over-cool a zone. If the cumulative cooling load delivered up to a given hour is as much as that delivered by the red cooling load profile, the zone will not be under-cooled. This approach achieves a major simplification in that the operative temperature response to every candidate cooling rate profile need not be calculated at every timestep to determine whether comfort conditions are met. Any precooling rate schedule that adheres to the constraints described above should maintain comfort conditions for that zone. The total cooling load on the chiller plant is the sum of such precooling rate schedules across all zones served by the plant, which yields similar minimum and maximum cooling load profiles for the entire cooling plant. 
Superimposing Figure 2 on Figure 1 shows the benefits of the TABS. Figure 3 shows the instantaneous cooling load profiles (dotted lines), the TABS-shifted precooling rate schedules (solid lines), and a near-optimal precooling rate schedule (red line) superimposed over a contour map of EIRs for each hour of the day (based on the temperature forecast) as a function of cooling rate. As shown in Figure 3, the original cooling load profiles, the dotted lines, delivered by a conventional system span the periods of the day with the highest outdoor temperatures and highest EIRs (lowest COPs). The TABS-shifted precooling rate schedules, the solid lines, span early hours of the day when the EIRs are lower (COPs higher) and greater chilled efficiencies are possible. The TABS can be designed to move the TABS-shifted precooling rate schedule relative to the EIR contour map (which could be generated for typical or average cooling season profiles) to allow cooling during the times of day when the chiller operates most efficiently.

Once these two bounds are set, an optimal precooling rate schedule (the red line) can be determined that is within the bounds of the maximum precooling rate schedule and provides at least the required cumulative load at each hour. Graphically, this can be thought of as filling the basin in Figure 1 such that the net cooling load is equivalent to the minimum base load, but the hourly precooling rate profile is constrained by the maximum precooling rate profile. This concept is shown in Figure 3, where the simplified optimal hourly cooling load is shown as a red line. The optimal load schedule stays within the maximum hourly precooling rate schedule, which limits the hours of operation and lowest achievable EIR in the early morning hours, and continues to cool up to a constant EIR where the remaining base cooling load can be met most efficiently, as reflected by the load schedule following the contour lines of the EIR map.

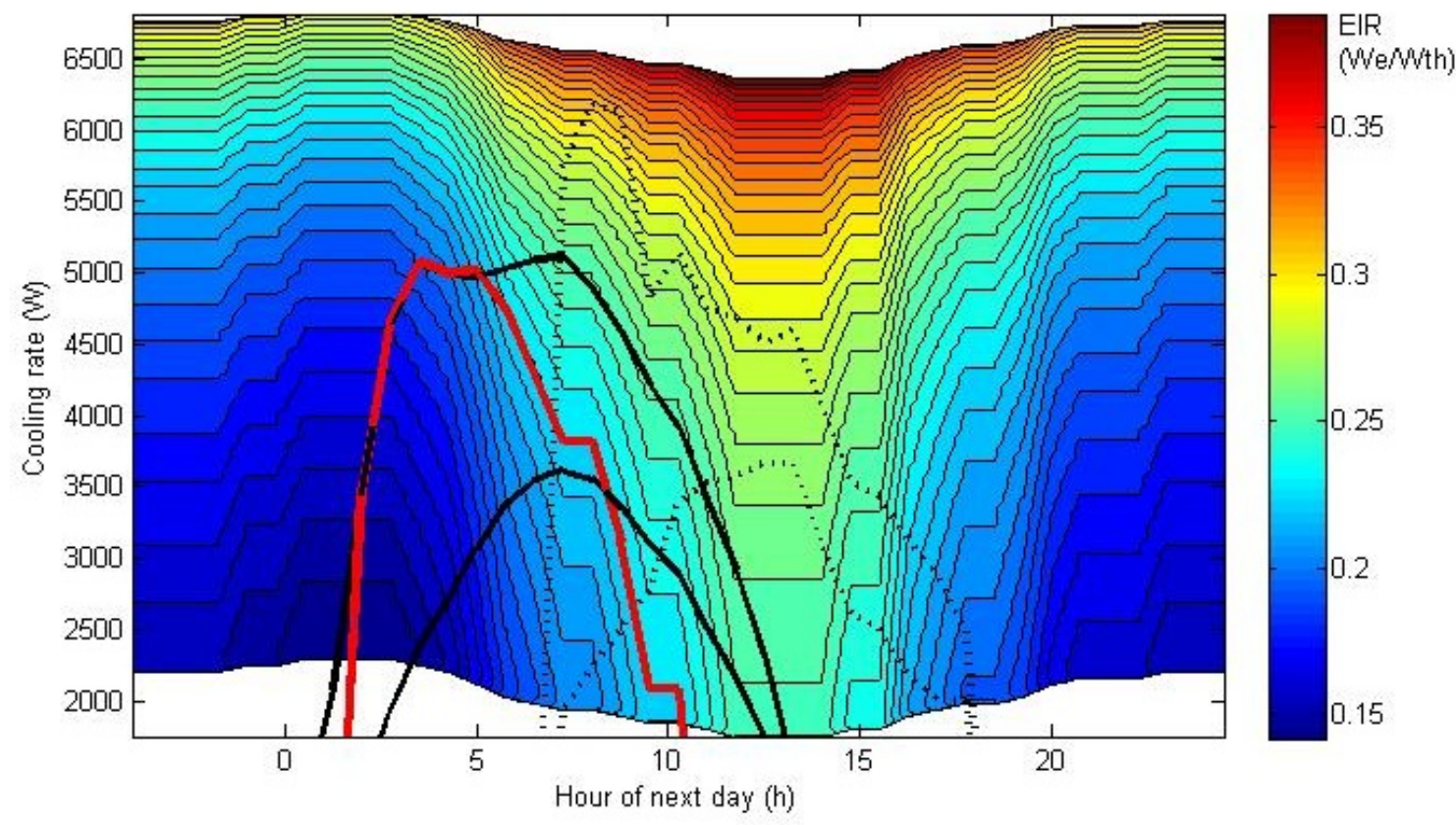

Figure 3. Contour map of possible EIR at each cooling rate for every hour of the day superimposed with the maximum and minimum instantaneous cooling load profiles (dotted lines), TABS-shifted precooling rate profiles (solid black lines), and simplified optimal precooling rate schedule (solid red line) 
The procedure illustrated above greatly simplifies the determination of the near optimal precooling rate schedule for a low-lift cooling system. The procedure requires that the BAS, or the chiller controller, contain a three-dimensional lookup table for the chiller EIR as a function of cooling rate, evaporating temperature, and outdoor air temperature. By assuming that the change in chilled-water temperature is negligible over the day, or that it is steadily decreasing by a few degrees, another three-dimensional lookup table can be created from the original lookup table whenever a new optimal precooling rate schedule is required. This lookup table provides the EIR as a function of cooling load at every hour of the day for a given outdoor temperature forecast as shown in Figure 3.

The maximum and minimum instantaneous cooling load schedules are identified from CRTFs and converted to TABS charging rate, or precooling rate, schedules using conduction transfer functions (CTFs) for the concrete slabs. The maximum precooling rate schedule constrains the allowed region within the time-of-day look up table, shown in Figure 4. The final step is to use the lookup table to determine the near optimal precooling rate schedule, within the allowed region, which provides the minimum cumulative cooling load. This is accomplished by summing the cooling rates at each hour along rows of the lookup table equal to or below a candidate maximum EIR for the day. The maximum EIR is increased (moving up a row in the lookup table) until the total minimum cooling load is met by the sum of all the loads at every hour at or below that maximum EIR.
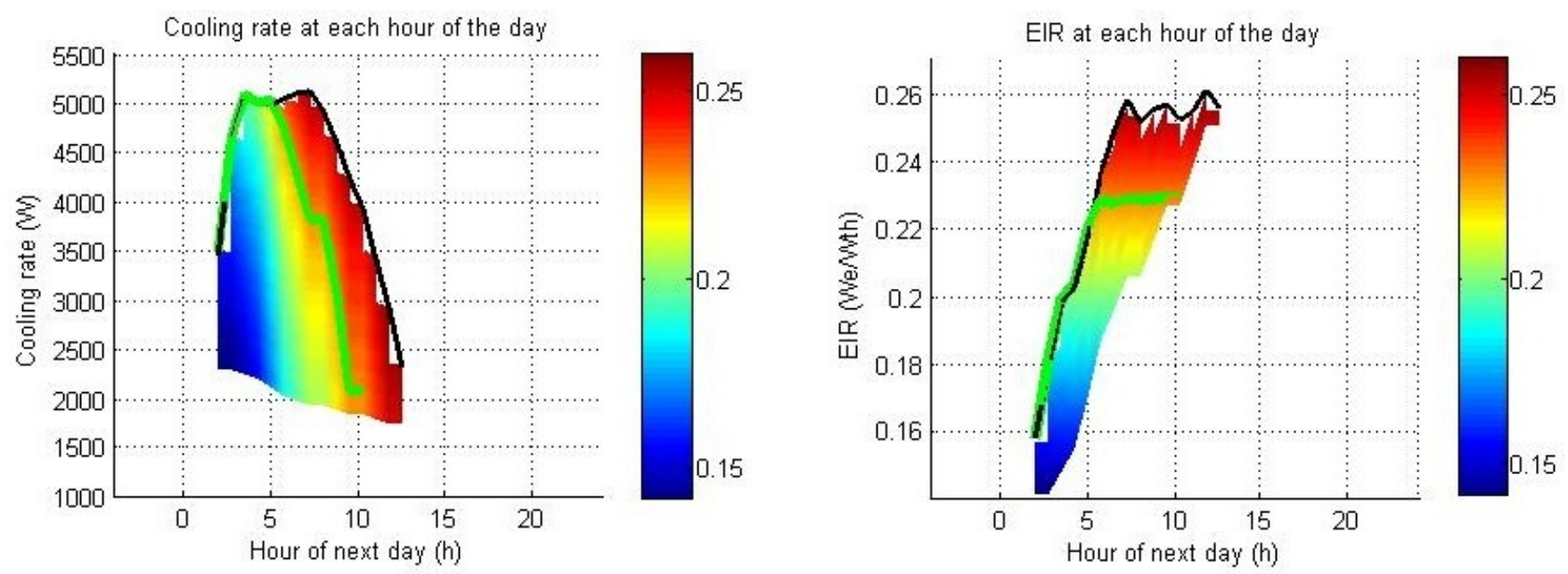

Figure 4. Optimal cooling rate (left) and EIR (right) at each hour of the day within the allowed region of operation (color map)

The result of this process is illustrated in Figure 5. The cumulative cooling load delivered for each candidate maximum EIR within the allowed region is shown on the left. The optimal 
operating point is the point with the lowest maximum EIR for the day that achieves the minimum cumulative cooling load for the day. The cumulative cooling delivered up to each hour of the day is shown as a black line in the center graph, which is bounded by the minimum and maximum cumulative cooling loads at each hour. Finally the resulting chiller power consumption is shown on the right.
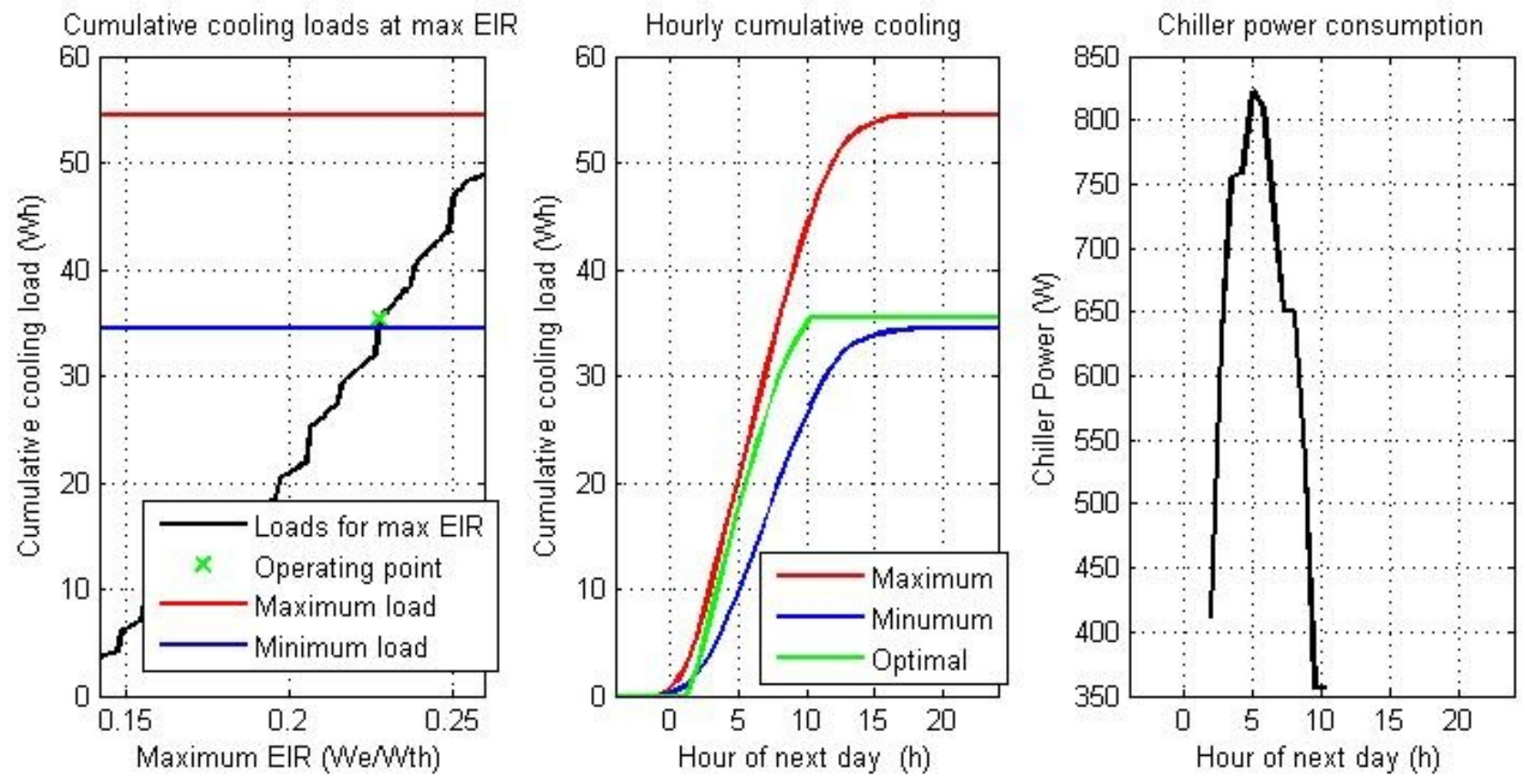

Figure 5. Cumulative cooling load for a given maximum EIR (left), optimal cumulative precooling rate at each hour of the day (center) and optimal chiller power consumption at each hour of the day

\subsection{Summary of Low-lift Cooling Model-predictive Control Algorithm}

For this task, the algorithms developed by Armstrong et al. (2009a) and Gayeski (2010) have been expanded to apply to multi-zone buildings with solar, occupant, and internal loads where zones may interact. Then, these algorithms were simplified by assuming the variation in chilledwater return temperature over the day was negligible relative to the variation in outdoor temperature and part-load ratio of the chiller. This assumption allowed for the creation of hourly chiller performance lookup tables from which an optimal low-lift precooling rate schedule could be easily looked up within an allowed operating region determined by comfort bounds. These comfort bounds are determined by linear CRTF and CTF models, which are simple sum-products of zone temperature and cooling flux histories. This simplified algorithm requires only mathematical functions such as sum, product, minimum and maximum, and the creation and evaluation of three-dimensional lookup tables. 


\section{Prototype Low-Lift Chiller Controller}

The objective of Task 2 was to develop and prototype a chiller controller that can accept supervisory commands from a conventional BAS to operate the chiller under model-based predictive control, and pre-cool the building thermal mass. This section details the work undertaken to develop and prototype such a controller on a suitable condensing unit that allows operation at low compressor speeds and pressure ratios, i.e., low-lift conditions, and under model-predictive control.

The objectives for this task were to:

- Design a prototype low-lift chiller controller that receives supervisory control commands from a BAS and provides control of compressor speed, condenser fan speed, and expansion valve positions,

- Design or modify a low-lift chiller control board to serve an existing variable capacity heat pump/chiller make and model,

- Fabricate and test the low-lift chiller control board,

- Test the controller's ability to accept supervisory control commands from an off-the-shelf control system and output the correct compressor, condenser fan and expansion valve control signals,

- Prepare a chiller control map to represent chiller power consumption, cooling rate, and efficiency as a function of outdoor air temperature, evaporating temperature/chilled-water temperature, compressor speed, and condenser fan speed.

A prototype low-lift chiller controller was designed, fabricated and tested to control a commercially available air-cooled chiller/heat pump condensing unit. The unit selected for modification and testing is a 3-ton refrigeration condensing unit with a rolling piston compressor that can be configured to supply as many as four evaporator units, including a brazed-plate heat exchanger to chill water. The rolling piston compressor is suitable for operation at low compressor speeds and low pressure ratios required for low-lift cooling (Gayeski et al. 2011a,Zakula et al. 2011). A picture of this condensing unit is shown in Figure 6. 


\subsection{Chiller Component Control}

There are three primary components that must be controlled to enable operation as a low-lift chiller. These are the compressor, condenser fan, and electronic expansion valves. To enable low-lift control, the internal PC board controller for the unit was removed from the control system and replaced with custom controllers for each of the three components. (Figure 7 shows one of the replacement controllers.)

The expansion valves are simple stepper motors for which control is trivial. The electronic components used for control are off-the-shelf components that could be immediately designed into the prototype lowlift controller. Similarly, achieving control over the condenser fan was accomplished using a standard brushless direct current motor controller.

The most difficult part of this task was to obtain control over the rolling piston compressor speed, to drive it at lower speeds and accept supervisory control commands from the BAS. Three approaches to this problem were researched and considered. The first option was to use a motor control microcontroller with a custom-closed loop control algorithm. The second option was to implement open-loop motor control using off-the shelf components, which have frequency limitations. Each of these options required interfacing with or replacing the drive elements for the compressor, requiring synthesizing pulse-width modulated inputs to drive the integrated power module (IPM), which drives the variable-speed compressor. Replacing the power board for a more efficient low-lift chiller variable-speed drive (or electrical convertor/inverter) was not a primary objective of this project, and as such, these two approaches were rejected because they require more extensive research to optimize an IPM for a wide range of speeds and higher efficiency at lower speeds. The existing IPM is efficient at a wide range of speeds, although its efficiency drops off somewhat at low speed based on measurements of similar IPMs. This was deemed acceptable for this project.

A third option was pursued by which the digital logic controlling the existing condensing unit inverter board is delivered by a custom high level logic controller. The existing power board receives the high level logic from the custom controller and implements the low-level logic required to control the IPM driving the compressor. This option was first prototyped and tested 
using only the components required for controlling the compressor. The test bench for the controller is shown in Figure 8. Once control over the compressor was achieved, a complete prototype controller could be designed.
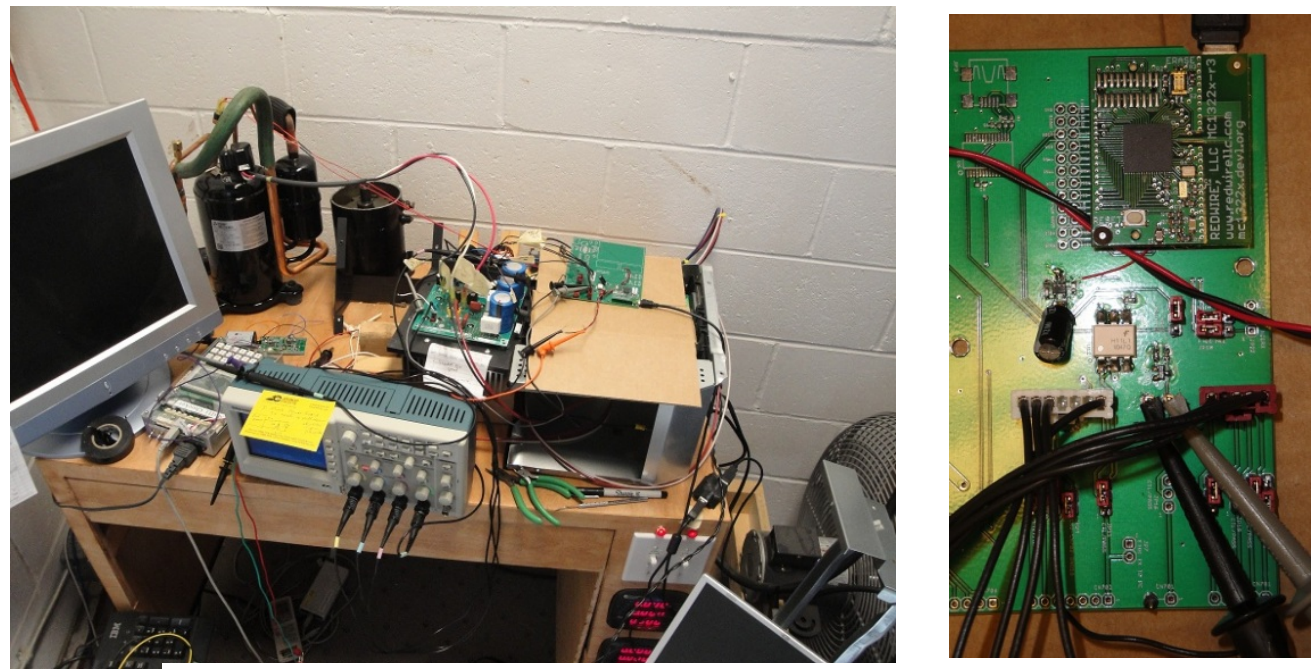

Figure 8. Compressor controller test bench and early control board prototype

\subsection{Low-lift Chiller Controller Design and Fabrication}

The final prototype controller can control the three major components of the low-lift chiller -- the compressor, condenser fan, and electronic expansion valves. Figure 9 shows the design for the prototype control board (left) and the fabricated board, prior to the installation of its electrical components (right). There are five primary functions incorporated into this board. The block on the upper right provides power to the board components as well as to the variable-speed condenser fan IPM. The block on the lower right is the supervisory controller interface, which can accept commands over RS-485 or wireless to control each component. On the left hand side, the block at the top controls the condenser fan, the block in the middle controls up to five electronic expansion valves, and the block at the bottom interfaces with the compressor power board.

A daughter board may be inserted in place of the PC board controller associated with the condensing unit, and will take over control for the compressor power module, expansion valves, and condenser fan and allow direct control from the BAS. Commanding the prototype controller over both RS-485 and wireless has been tested. 

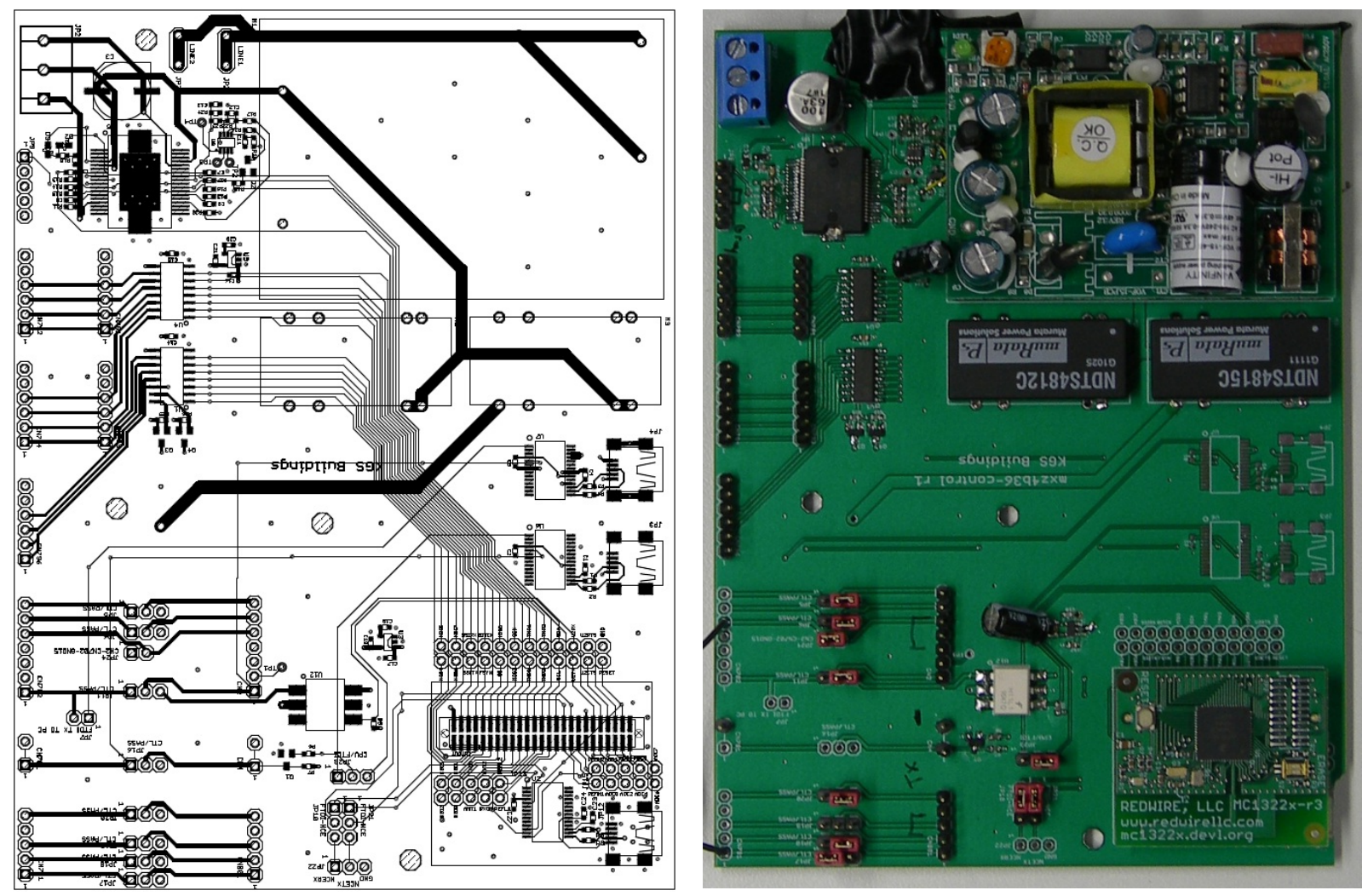

Figure 9. Prototype control board design and fabricated board

\subsection{Low-lift Chiller Performance Curve}

The final component of this task is to identify a chiller performance model that can inform the predictive control algorithm used to determine compressor and condenser fan speed. The chiller performance model for this work is derived from a model of a smaller air-cooled condensing unit studied in detail through experimentation by Gayeski (2010). There are three quad-cubic models of chiller cooling capacity, power consumption, and energy input ratio (EIR), the reciprocal of the coefficient of performance (COP), used to describe the performance of the condensing unit at different outdoor air temperatures $T_{x}$, evaporating temperatures $T_{e}$, compressor speeds $\omega_{c}$, and condenser fan speeds $\mathrm{f}$. These models were generated by testing a rolling-piston compressor condensing unit at 131 steady-state conditions with a7 percent heat balance accuracy. The unit tested had a rated capacity of 9,000 Btu/hr and a rated power consumption of $690 \mathrm{~W}$.

The models generated by Gayeski (2010) have been scaled to match the rated capacity, power consumption, and EIR of the specific condensing unit used to develop the prototype controller. The unit used in this research has a rated capacity of 36,000 Btu/hr, with a rated power consumption of $3760 \mathrm{~W}$. Although these units are both rolling-piston compressor condensing units produced by the same manufacturer, a more accurate performance model may be 
determined by further experiments or modeling from physical engineering data beyond the scope of the current research.

The performance curves are of the form shown in equation (19), where DV is the dependent variable, which can be cooling capacity $Q$, power consumption $P$, or energy input ratio EIR. The coefficients for these curves are shown in Table 1. For the condensing unit used in this research $\mathrm{Q}_{\text {rated }}$ is $10,375 \mathrm{~W}, \mathrm{P}_{\text {rated }}$ is $3760 \mathrm{~W}$, and EIR rated is 0.36 .

$$
D V=D V_{\text {rated }}\left(\begin{array}{l}
C_{1}+C_{2} T_{e}+C_{3} T_{x}+C_{4} \omega+C_{5} T_{e}^{2}+C_{6} T_{x}^{2}+C_{7} \omega^{2}+C_{8} T_{e} T_{x}+C_{9} T_{e} \omega+C_{10} T_{x} \omega+ \\
C_{11} T_{e}^{3}+C_{12} T_{x}^{3}+C_{13} \omega^{3}+C_{14} T_{e}^{2} T_{x}+C_{15} T_{e}^{2} \omega+C_{16} T_{x}^{2} T_{e}+C_{17} T_{x}^{2} \omega+ \\
C_{18} \omega^{2} T_{e}+C_{19} \omega^{2} T_{x}+C_{20} T_{e} T_{x} \omega+C_{21} f+C_{22} f^{2}+C_{23} f T_{e}+C_{24} f T_{x}+C_{25} f \omega
\end{array}\right)
$$

\subsection{Summary of Low-lift Chiller Controller Development}

The objective of this task was to develop, fabricate and test a prototype low-lift chiller controller that could be used to control a specific condensing unit suitable for a low-lift cooling demonstration. An electronic control board that accepts supervisory commands from a BAS has been designed, fabricated and tested to control compressor speed and condenser fan speed for a multi-evaporator, air-cooled condensing unit suitable for use as a low-lift chiller in a small demonstration project. 
Table 1. Chiller performance curve coefficients for $T$ given in ${ }^{\circ} \mathrm{C}, \omega$ given in $\mathrm{Hz}$ and $\mathrm{f}$ given in rpm

\begin{tabular}{|l|l|r|r|r|}
\multicolumn{1}{l}{ Term } & \multicolumn{1}{c}{ Multiplier } & \multicolumn{1}{c}{$\mathrm{EIR}$} & \multicolumn{1}{c}{$\mathrm{P}$} \\
\hline $\mathrm{C}_{1}$ & Constant & $8.83 \mathrm{E}-02$ & $2.86 \mathrm{E}-01$ & $1.88 \mathrm{E}-02$ \\
\hline $\mathrm{C}_{2}$ & $\mathrm{~T}_{\mathrm{e}}$ & $4.89 \mathrm{E}-02$ & $-6.26 \mathrm{E}-02$ & $3.78 \mathrm{E}-02$ \\
\hline $\mathrm{C}_{3}$ & $\mathrm{~T}_{\mathrm{x}}$ & $2.23 \mathrm{E}-02$ & $7.51 \mathrm{E}-03$ & $1.49 \mathrm{E}-02$ \\
\hline $\mathrm{C}_{4}$ & $\omega_{\mathrm{c}}$ & $2.21 \mathrm{E}-02$ & $2.60 \mathrm{E}-03$ & $-3.06 \mathrm{E}-03$ \\
\hline $\mathrm{C}_{5}$ & $\mathrm{~T}_{\mathrm{e}}{ }^{2}$ & $-5.12 \mathrm{E}-03$ & $5.76 \mathrm{E}-03$ & $-2.16 \mathrm{E}-03$ \\
\hline $\mathrm{C}_{6}$ & $\mathrm{~T}_{\mathrm{x}}{ }^{2}$ & $-5.24 \mathrm{E}-04$ & $3.83 \mathrm{E}-04$ & $-9.39 \mathrm{E}-04$ \\
\hline $\mathrm{C}_{7}$ & $\omega_{\mathrm{c}}{ }^{2}$ & $-2.63 \mathrm{E}-04$ & $3.26 \mathrm{E}-04$ & $1.90 \mathrm{E}-04$ \\
\hline $\mathrm{C}_{8}$ & $\mathrm{~T}_{\mathrm{e}}{ }^{*} \mathrm{~T}_{\mathrm{x}}$ & $1.02 \mathrm{E}-03$ & $-2.47 \mathrm{E}-03$ & $3.20 \mathrm{E}-05$ \\
\hline $\mathrm{C}_{9}$ & $\mathrm{~T}_{\mathrm{e}}{ }^{*} \omega$ & $-1.77 \mathrm{E}-03$ & $2.97 \mathrm{E}-03$ & $-1.00 \mathrm{E}-03$ \\
\hline $\mathrm{C}_{10}$ & $\mathrm{~T}_{\mathrm{x}}{ }^{*} \omega$ & $2.79 \mathrm{E}-04$ & $-6.29 \mathrm{E}-04$ & $8.78 \mathrm{E}-04$ \\
\hline $\mathrm{C}_{11}$ & $\mathrm{~T}_{\mathrm{e}}{ }^{3}$ & $1.17 \mathrm{E}-04$ & $-1.46 \mathrm{E}-04$ & $3.81 \mathrm{E}-05$ \\
\hline $\mathrm{C}_{12}$ & $\mathrm{~T}_{\mathrm{x}}{ }^{3}$ & $1.64 \mathrm{E}-05$ & $5.04 \mathrm{E}-07$ & $1.21 \mathrm{E}-05$ \\
\hline $\mathrm{C}_{13}$ & $\omega_{\mathrm{c}}{ }^{3}$ & $1.64 \mathrm{E}-06$ & $-2.43 \mathrm{E}-06$ & $-2.41 \mathrm{E}-07$ \\
\hline $\mathrm{C}_{14}$ & $\mathrm{~T}_{\mathrm{e}}{ }^{2}{ }^{*} \mathrm{~T}_{\mathrm{x}}$ & $-4.74 \mathrm{E}-05$ & $9.44 \mathrm{E}-05$ & $-1.00 \mathrm{E}-05$ \\
\hline $\mathrm{C}_{15}$ & $\mathrm{~T}_{\mathrm{e}}{ }^{2 *} \omega_{\mathrm{c}}$ & $8.22 \mathrm{E}-05$ & $-8.38 \mathrm{E}-05$ & $2.65 \mathrm{E}-05$ \\
\hline $\mathrm{C}_{16}$ & $\mathrm{~T}_{\mathrm{x}}{ }^{2 *} \mathrm{~T}_{\mathrm{e}}$ & $-3.98 \mathrm{E}-06$ & $-2.27 \mathrm{E}-05$ & $6.13 \mathrm{E}-06$ \\
\hline $\mathrm{C}_{17}$ & $\mathrm{~T}_{\mathrm{x}}{ }^{2 *} \omega_{\mathrm{c}}$ & $-1.81 \mathrm{E}-06$ & $-5.31 \mathrm{E}-06$ & $-3.25 \mathrm{E}-06$ \\
\hline $\mathrm{C}_{18}$ & $\omega^{2 *} \mathrm{~T}_{\mathrm{e}}$ & $1.19 \mathrm{E}-05$ & $-2.05 \mathrm{E}-05$ & $7.62 \mathrm{E}-06$ \\
\hline $\mathrm{C}_{19}$ & $\omega^{2 *} \mathrm{~T}_{\mathrm{x}}$ & $7.84 \mathrm{E}-07$ & $4.36 \mathrm{E}-06$ & $-3.33 \mathrm{E}-06$ \\
\hline $\mathrm{C}_{20}$ & $\mathrm{~T}_{\mathrm{e}}{ }^{*} \mathrm{~T}_{\mathrm{x}}{ }^{*}$ & $-2.55 \mathrm{E}-05$ & $3.56 \mathrm{E}-05$ & $-4.26 \mathrm{E}-07$ \\
\hline $\mathrm{C}_{21}$ & $\mathrm{\omega}_{\mathrm{c}}$ & $-7.53 \mathrm{E}-04$ & $1.30 \mathrm{E}-04$ & $-4.00 \mathrm{E}-04$ \\
\hline $\mathrm{C}_{22}$ & $\mathrm{f}^{2}$ & $7.65 \mathrm{E}-07$ & $-1.10 \mathrm{E}-07$ & $4.42 \mathrm{E}-07$ \\
\hline $\mathrm{C}_{23}$ & $\mathrm{f}_{25} \mathrm{~T}_{\mathrm{x}}$ & $1.03 \mathrm{E}-06$ & $3.43 \mathrm{E}-06$ & $-4.91 \mathrm{E}-07$ \\
\hline $\mathrm{C}_{24}$ & $\mathrm{f}^{*} \mathrm{~T}_{\mathrm{e}}$ & $-4.24 \mathrm{E}-06$ & $-7.66 \mathrm{E}-07$ & $-2.59 \mathrm{E}-06$ \\
\hline $\mathrm{f}_{\mathrm{c}}$ & $-8.41 \mathrm{E}-06$ & $2.05 \mathrm{E}-06$ & $-5.04 \mathrm{E}-06$ \\
\hline
\end{tabular}




\section{Low-lift Control through a Commercial BAS}

To test the model-predictive control algorithms and associated data-driven temperature response models described above, two Building Controls Virtual Test Bed (BCVTB) (LBNL 2011) files have been created to simulate the model identification process for a TABS building with low-lift cooling and the control algorithm commanding the prototype chiller controller. To test the model identification methods described in Section 2, a model of a three-zone building with a low-temperature radiant system in each zone has been adapted from EnergyPlus, which simulates a low-lift cooling system with TABS. A MATLAB ${ }^{\circledR}$ code identifies the multi-zone temperature response models described in equations (2) through (12) from this building simulation.

The BCVTB runs the EnergyPlus model to simulate the low-lift cooling system and, at each timestep, passes 'measured' data from EnergyPlus to MATLAB ${ }^{\circledR}$. The MATLAB ${ }^{\circledR}$ code then identifies the coefficients of data-driven models, shown in equations (2) through (12) of the building simulated in EnergyPlus. These CRTF models are then available to predict the temperature response of the building (in this case the simulated building in EnergyPlus) to predicted conditions and any future sequence of control actions. The CRTF models can thus be used, along with the chiller performance map described in Section 3, to inform the simplified low-lift control algorithm. A screen shot of the low-lift system model identification test in BCVTB, using EnergyPlus and MATLAB ${ }^{\circledR}$, is shown in Figure 10.

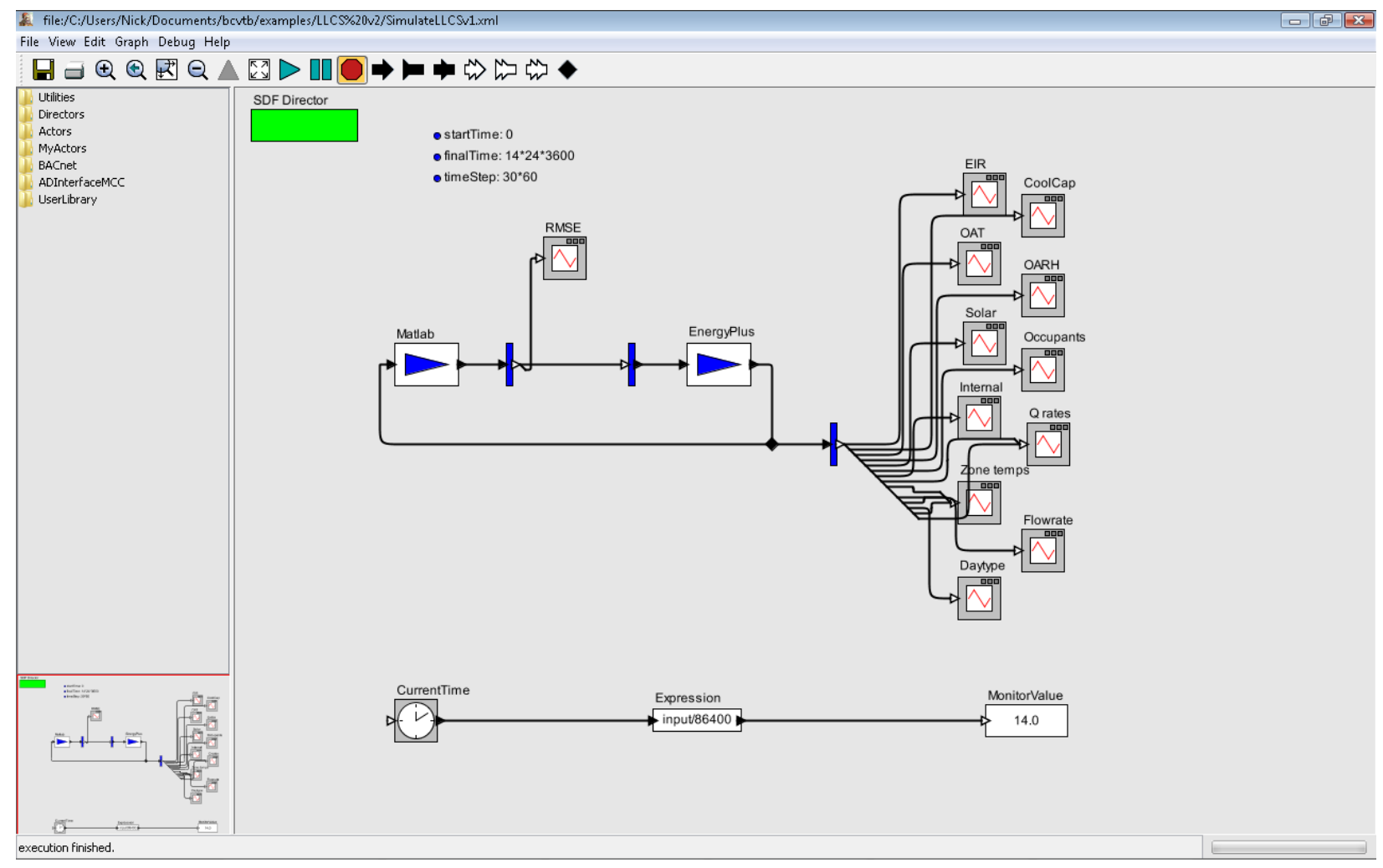

Figure 10. BCVTB simulation for low-lift cooling model identification 
To test the simplified low-lift cooling control algorithms and test communication with the prototype low-lift chiller controller from a BAS, a second BCVTB model was created hat utilizes MATLAB ${ }^{\circledR}$ to simulate the building performance, based on the identified CRTF models and low-lift chiller model, and a BACnet writer to communicate with the NCE25 supervisory controller from which commands can be sent to the prototype chiller controller. An image of this BCVTB system is shown in Figure 11.

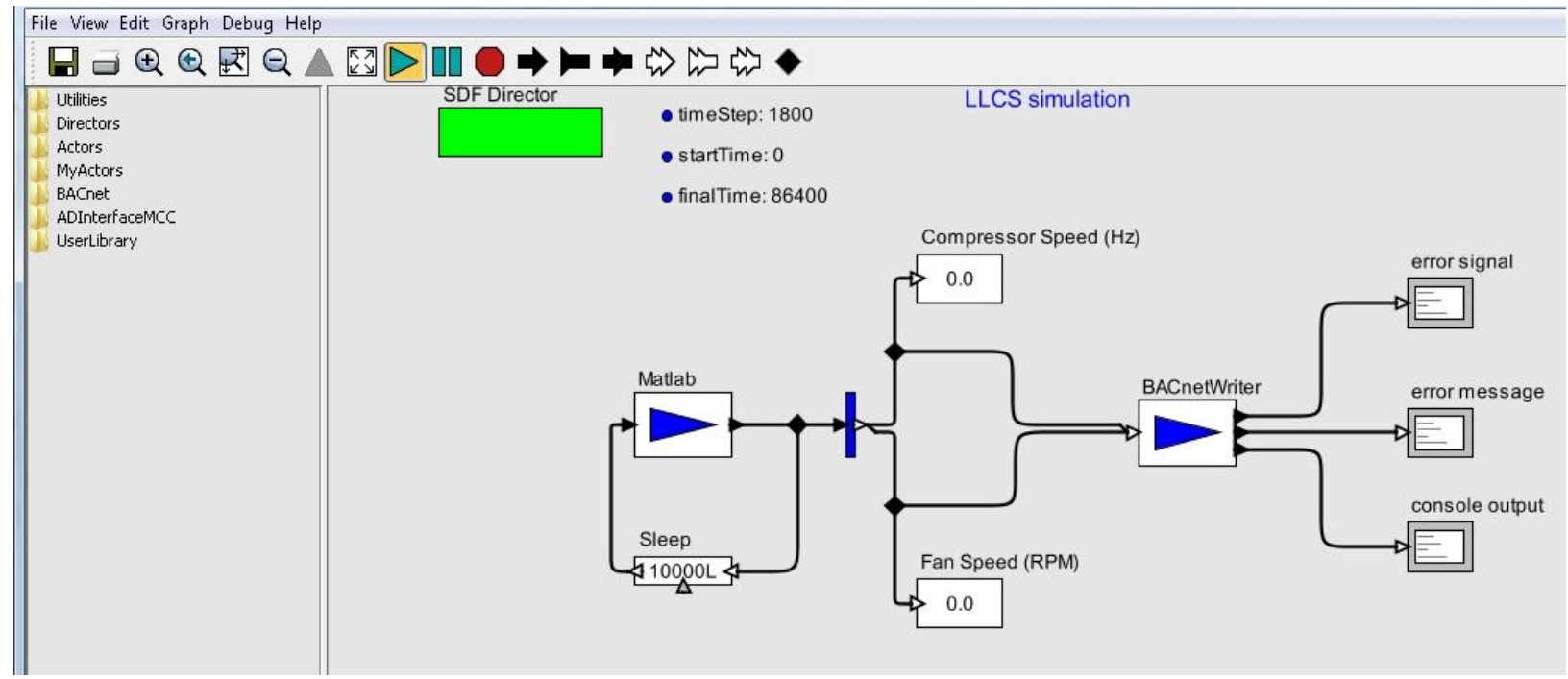

Figure 11. BCVTB simulation for simplified low-lift control implementation through the NCE25 to the prototype chiller controller

The BCVTB system shown above simulates the performance of a multi-zone building with lowlift cooling and the performance of its low-lift chiller in MATLAB ${ }^{\circledR}$. The simulation can be configured to run for any period of time, such as 1 day or 1 week. At each simulation timestep, compressor speed and condenser fan speed commands are displayed and sent over BACnet to the NCE25 controller. Trending from the NCE25 controller of the compressor and condenser fan speed points are shown in Figure 12. The NCE25 controller can then communicate these commands to the prototype controller over an RS485 connection. To couple the simulation with the actual prototype controller and low-lift chiller, the simulation can be paused for an arbitrary period to allow the chiller to operate at the specified conditions for a given amount of time. Such a simulation could be deployed on a real building, with the prototype low-lift chiller and controller, to allow for model-predictive control from the BCVTB. 


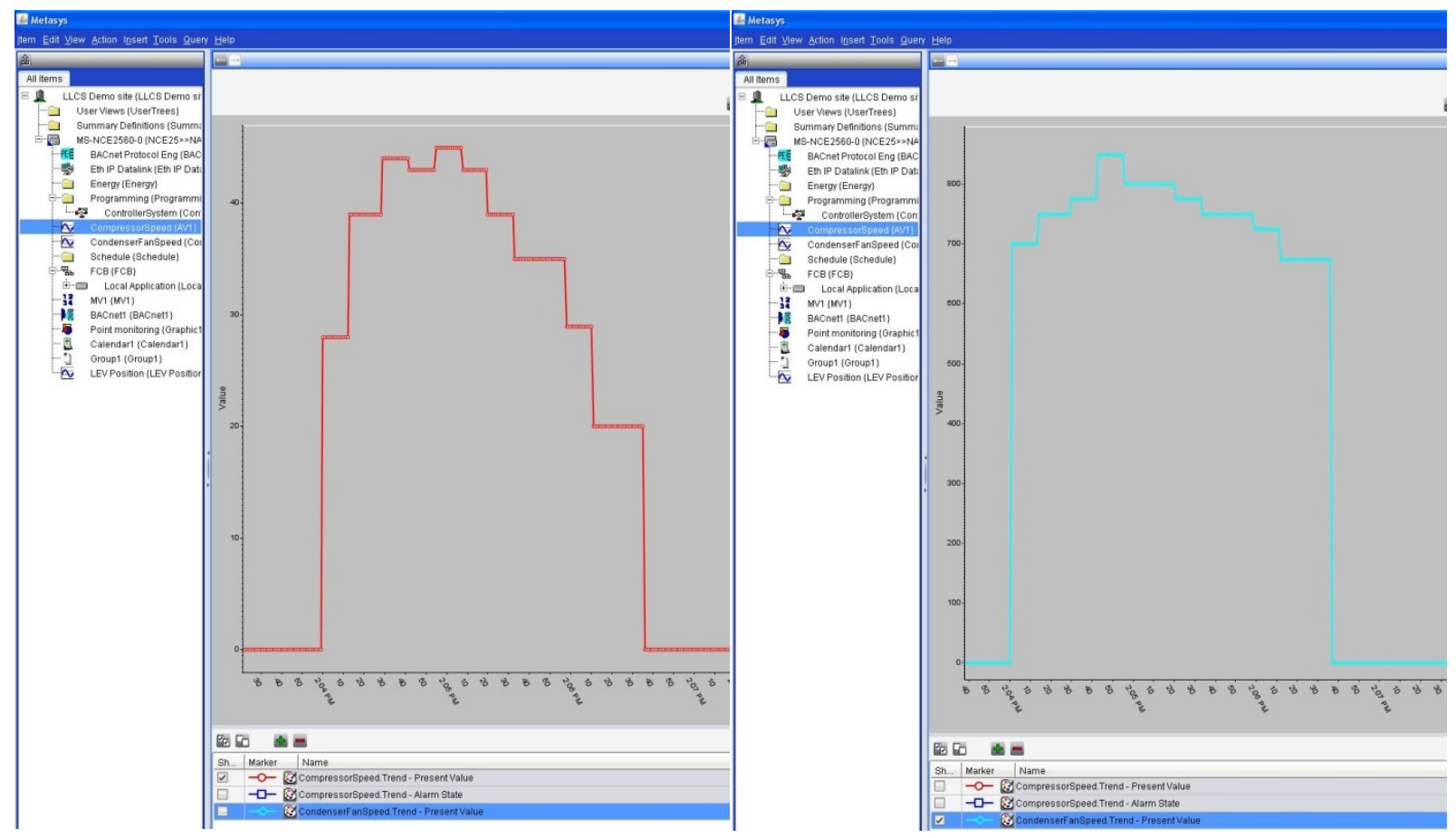

Figure 12. Compressor speed (left) and condenser fan speed (right) point trending in the NCE25 BAS controller, receiving commands over BACnet from the low-lift control algorithm implemented in MATLAB ${ }^{\circledR}$ through the BCVTB

Ultimately, the simplified low-lift control algorithm can be implemented as a program in a commercial BAS that allows for simple math functions and lookup tables described in the previous section. For development and demonstration purposes, allowing for control algorithm testing and modification through the BCVTB is a natural first step towards coding the algorithms in a BAS.

Another path for implementation of the low-lift control algorithm is to embed the algorithm as a dll (dynamically linked library) file on the low-lift chiller controller itself. The controller chip would receive the necessary measured inputs from the BAS, identify a data-driven model of the zones the chiller serves, and utilize a pre-configured lookup table of chiller performance to perform the simplified model-predictive control optimization.

An additional implementation option is to separate the model-predictive supervisory control logic from the chiller and BAS entirely by leveraging new technologies such as cloudcomputing. A cloud-based supervisory control platform, with computational resources to implement complicated model-predictive control algorithms, could be connected to a BAS to communicate high-level logic on a daily basis to command the low-lift chiller. This approach would require a fail-safe low-lift control algorithm which, for example, delivered a sub-optimal base cooling load to the building in the event communications failed. 


\section{Low-Lift Cooling Field Test Opportunities}

This section describes options and technical requirements for a field test of low-lift cooling systems (LLCS). The objective of this task is to plan a full-scale demonstration project, or field test, of LLCS to assess the achievable cooling energy savings in a full-scale building, overcome technical challenges to installing and operating LLCS, and advance LLCS towards commercialization.

\subsection{Field Test Site Opportunities}

We are currently pursuing the four options for an LLCS field test described below in Sections 5.1.1 through 5.1.4.

\subsubsection{Greater Philadelphia Innovation Cluster (GPIC) Hub for Energy Efficient Buildings}

The LLCS research team has been communicating regularly with Timothy Wagner, the Integrated Technologies Lead at the GPIC Hub to discuss incorporating an LLCS field test into building retrofits or new construction at the GPIC Hub. The GPIC team has indicated that a process for including research projects and proposals from external research teams is currently under development. The Urban Outfitters offices, which will be developed at the GPIC Hub site, would be a suitable location for an LLCS field test. A portion of the office space could be equipped with concrete-core radiant cooling served by low-lift chillers and a dedicated outdoor air system (DOAS). The entire office building need not be used for an LLCS field test. This is the best possible location for a domestic LLCS field test, but the administrative hurdles to conducting the field test are as yet unclear. The GPIC Hub has indicated that a field test may not be practical until fiscal year 2013 and would require approval among the many projects submitted for review (UTRC 2011).

\subsubsection{Collaboration with the Masdar Institute of Science and Technology}

The Masdar Institute of Science and Technology has begun construction on a full-scale laboratory test facility equipped with a concrete-core radiant cooling system. The low-lift chiller and controls required for this field test have not yet been identified, developed or planned. The research conducted by PNNL and KGS could support design and implementation of the low-lift cooling test facility at Masdar City in Abu Dhabi by providing necessary control algorithms, low-lift chiller control hardware, and system integration support (Masdar 2011).

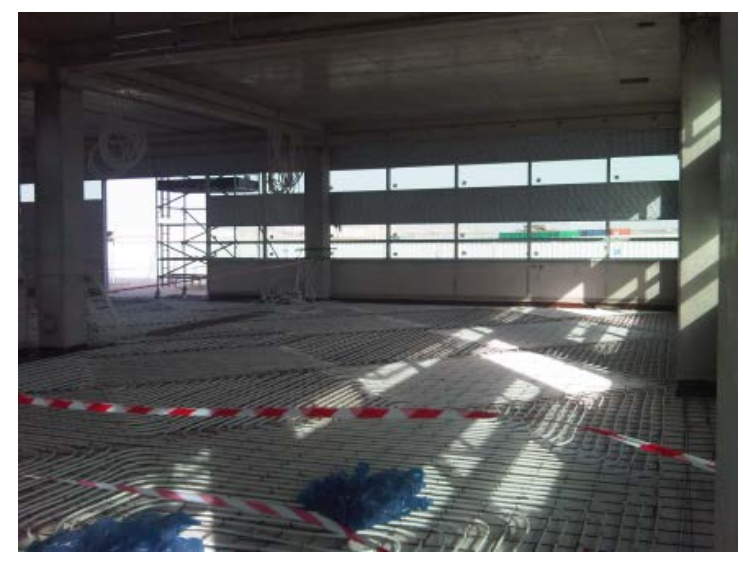

Figure 13. Masdar Institute low-lift cooling field test site progress 


\subsubsection{CEMEX San Bernabos Community Center in Monterrey, Mexico}

CEMEX, a global building materials company has contacted KGS about incorporating a low-lift cooling system into a community center project in Monterrey, Mexico. Currently, the project design architect and engineering team have reviewed the low-lift cooling concept and are in discussions with KGS about integrating the system into one of the buildings (Building \#1) at the San Bernabos Community Center (CEMEX 2011).

\subsubsection{Field Test in Collaboration with Shine Engineering and EVCO Mechanical}

Shine Engineering, a New Jersey based engineering firm, and EVCO Mechanical, a New Jersey based mechanical contractor, have expressed strong interest in supporting a field test of LLCS in their projects. Three projects had been identified with potential for an LLCS field test, including an affordable housing development, a hotel retrofit, and a small commercial office building retrofit. These projects have advanced beyond the stage of design development, when it would be suitable to integrate an LLCS field test design. However, interest remains at these firms to collaborate on an LLCS field test, but their commitment will not be possible until a timeline and a budget for supporting the field test are in place (EVCO 2011).

\subsection{Field Test Site Design Concept}

The preliminary field test design involves installing small capacity low-lift chillers serving roughly three zones, such as an office space, with radiant concrete-core floor slabs and served by a DOAS for ventilation and dehumidification. This modular design, although suitable for a small demonstration project, is also scalable to include many zones and can be adapted to a variety of potential field test scenarios. Each chiller can be equipped with a low-lift chiller control board. The prototype low-lift chiller control board can interface with conventional BAS through an RS485 connection. The simplified low-lift control algorithm can be implemented within the BAS or externally with high-level supervisory commands to the BAS. For example, a field demonstration might employ the BCVTB implementation described in Section 4 to commission the low-lift control algorithm for use at full-scale. Conceptual schematics for the radiant concrete-core cooling system served by a low-lift chiller and the control system network are included as Appendix A.

The preliminary design shown in Appendix A is suitable for new construction or retrofit, wherein the concrete-core radiant slab will be installed as a topping slab above an existing floor. Practical considerations such as window sill height requirements, floor-to-floor height requirements, structural load constraints, and elevator openings will place constraints on retrofit projects. Close collaboration with a qualified and supporting project engineer, architect, and mechanical contractor will be critical to the success of the LLCS field test.

\subsection{Low-lift Cooling Target Market}

The initial target market for the LLCS field test is the medium-size commercial office building sector, as justified by the market assessment described in Katipamula et al. (2010), which estimates that LLCS have an incremental cost savings of \$0.58/sf relative to multi-zone rooftop unit systems in medium-sized commercial office buildings. The preliminary design for a 
modular LLCS is similar to increasingly prevalent variable refrigerant flow (VRF) split-system air conditioning systems being installed in small and medium offices, but that do not leverage thermal energy storage or predictive control to achieve the significant energy savings enabled by LLCS. LLCS are a more efficient alternative in office buildings, where VRF systems are already an option for new construction or retrofit.

A budget for conducting a low-lift field demonstration/test will depend on the option chosen. The budget will include the cost for a research engineer to work with a project mechanical engineer and mechanical contractor to integrate an LLCS into a medium-sized commercial building renovation or new construction project. It will also include the cost for conducting LLCS field tests and necessary measurement and instrumentation costs. The budget will not include the LLCS system installation, equipment or hardware costs, which must be covered by the building owner or developer. There is a possibility that the owner or developer may ask the project to fund some portion of the incremental cost, if the LLCS option costs are higher than the conventional system option. Enlisting the participation of a building owner or developer willing to accept the additional risk, project delay, and inconvenience of field testing is crucial to the success of the field test and may necessitate additional costs. 


\section{Summary}

In this research a simplified control algorithm and prototype low-lift chiller controller suitable for model-predictive supervisory control of low-lift cooling systems have been developed to support a field test. The work addresses two barriers to achieving commercially viable low-lift cooling systems. The first barrier is the lack of low-lift chillers that can operate efficiently over a wide range of part-load capacity and at low pressure ratios and the ability to be controlled externally for static optimal control under a given set of temperature and load conditions. The second barrier is the lack of a simple low-lift cooling model-predictive control algorithm for TABS-based multi-zone buildings that can be implemented in a commercial BAS. The research addressed these barriers through four tasks.

In Task 1, described in Section 2, the control algorithms developed by Armstrong et al. (2009a,b) and Gayeski (2010) were expanded to include all expected loads in a typical multi-zone building and simplified to exclude complex optimization solvers so that they can be readily implemented in a BAS. The simplified predictive pre-cooling control algorithm includes predictions of thermal loads such as solar, occupant, internal, and temperature-driven loads for a multi-zone low-lift cooling system. The algorithm has been simplified to allow for implementation in a BAS using simple look up tables and conventional math functions.

In Task 2, described in Section 3, a prototype low-lift chiller controller was designed and fabricated to operate a commercially available variable-speed chiller through supervisory commands from a BAS. Redwire, LLC in collaboration with KGS designed, fabricated and tested a low-lift chiller control board that can control a suitable condensing unit as a low-lift chiller. Condensing units with inverter/permanent magnet-motor-driven rolling-piston compressors were selected because of their ability to operate efficiently over a wide speed range and at very low pressure ratios. The prototype controller can accept commands wirelessly or over an RS485 connection from any BAS controller.

In Task 3, supervisory control commands from the simplified low-lift control algorithm were communicated from the BCVTB via BACnet to a commercial BAS controller, which can communicate with the prototype chiller controller. In lieu of a low-lift cooling system in a real building, an EnergyPlus simulation was used to identify CRTF models of the zone temperature response of a building with a concrete-core radiant floor. BCVTB and MATLAB ${ }^{\circledR}$ were used to simulate the operation of the low-lift chiller driving the CRTF zone temperature response models and to implement the simplified low-lift cooling control algorithm. Commands at each timestep were communicated to the NCE25 supervisory BAS controller. The simplified model-predictive control algorithm for 24-hour ahead near optimal capacity dispatch includes only lookup tables for chiller performance and conventional math functions, which could be implemented in a modern BAS.

Finally, in Task 4, low-lift cooling field test sites and design options were reviewed Currently, options for a field test include the Greater Philadelphia Innovation Cluster (GPIC) Hub, a collaboration with the Masdar Institute of Science and Technology, a joint project with CEMEX, and private projects in collaboration with EVCO Mechanical and Shine Engineering. The most appropriate domestic option for a field test is the GPIC Hub, but it is unlikely that a field test at 
the Hub will be possible until 2013 and would require approval by the GPIC Hub. The most immediate opportunity for a field test is at Masdar City, in Abu Dhabi, where PNNL and KGS could work with researchers at the Masdar institute to implement and field test a low-lift cooling systems utilizing the control algorithms and controller developed in this research. 


\section{References}

Armstrong P.R., S.B. Leeb, and L.K. Norford. 2006a. Control with Building Mass - Part I: Thermal Response Model. ASHRAE Transactions Vol. 112(1).

Armstrong P.R., S.B. Leeb, and L.K. Norford. 2006b. Control with Building Mass - Part II: Simulation. ASHRAE Transactions Vol. 112(1).

Armstrong, P.R., W. Jiang, D.W. Winiarski, S. Katipamula, L.K. Norford, and R.A. Willingham. 2009a. Efficient Low-Lift Cooling with Radiant Distribution, Thermal Storage and Variable-Speed Chiller Controls - Part I: Component and Subsystem Models. ASHRAE HVAC\&R Research, 15(2):366-401.

Armstrong, P. R., W. Jiang, D.W. Winiarski, S. Katipamula, L.K. Norford, and R.A.Willingham. $2009 b$. Efficient Low-Lift Cooling with Radiant Distribution, Thermal Storage and Variable-Speed Chiller Controls - Part II Annual Energy Use and Savings. ASHRAE HVAC\&R Research, 15(2):402-432.

CEMEX 2011. Personal communication with Enrique Terrado.

EVCO 2011. Personal communication with Evan Samouhos.

Gayeski, N.T. 2010. Predictive Pre-cooling Control for Low-Lift Radiant Cooling Using Building Thermal Mass. Ph.D. Dissertation. Massachusetts Institute of Technology, Cambridge Massachusetts.

Gayeski, N.T.,T. Zakula, P.R. Armstrong, and L.K. Norford. 2011a. Empirical Modeling of a RollingPiston Compressor Heat Pump for Predictive Control in Low-Lift Cooling. ASHRAE Transactions 117(2).

Gayeski, N.T., P.R. Armstrong, and L.K. Norford. 2012. Predictive Pre-cooling of Thermo-active Building Systems with Low-Lift Chillers. HVAC\&R Research DOI: 10.1080/10789669.2012.643752

Jiang, W., D.W. Winiarski, S. Katipamula, and P.R. Armstrong. 2007. Cost Effective Integration of Low Lift Cooling Technologies. PNNL-17157. Pacific Northwest National Laboratory, Richland, Washington.

Katipamula, S., P.R. Armstrong, W. Wang, N. Fernandez, H. Cho, W. Goetzler, J. Burgos, R. Radhakrishnan, and C. Ahlfeldt. 2010. Cost-Effective Integration of Efficient Low-Lift Baseload Cooling Equipment. PNNL-19114. Pacific Northwest National Laboratory, Richland, Washington.

Lawrence Berkeley National Laboratory (LBNL). 2011. Building Controls Virtual Test Bed. Lawrence Berkeley National Laboratory, Livermore, California. < <https:// http://simulationresearch.lbl.gov/bcvtb>

Masdar 2011. Personal communication with Afshin Afshari.

UTRC 2011. Personal communication with Timothy Wagner.

Zakula, T., N.T. Gayeski, P.R. Armstrong, and L.K. Norford. 2011. Variable-Speed Heat Pump Model for a Wide Range of Cooling Conditions and Loads. HVAC\&R Research, 17:5, 670-691 


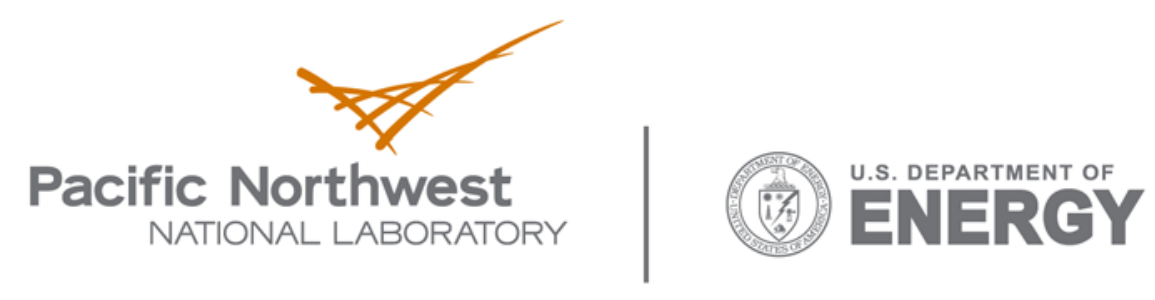

902 Battelle Boulevard

P.O. Box 999

Richland, WA 99352

1-888-375-PNNL (7665)

www.pnl.gov 